\title{
Heterochromatin Replication: Direct Interaction of DNA replication machinery with heterochromatin code writer Clr4/Suv39 and reader Swi6/HP1 in S. pombe
}

\author{
Sharanjot Saini ${ }^{1}$, Sumit Arora, Kamlesh K. Bisht ${ }^{2}$, Nandni \\ Nakwal, Shakil Ahmed ${ }^{3}$ and Jagmohan Singh* \\ Institute of Microbial Technology, Sector 39A, \\ Chandigarh 160036, India
}

\begin{abstract}
${ }^{1}$ Department of Biochemistry and Molecular Biology, 1410 Laney Walker Blvd. Augusta, GA 30909. USA

${ }^{2}$ Translational Development and Diagnostics, Celgene Corporation, 556 Morris Avenue, Summit, NJ, 07901, USA

${ }^{3}$ Central Drug Research Institute, Lucknow (UP) India
\end{abstract}

${ }^{*}$ Address correspondence to:

Institute of Microbial Technology, Sector 39A, Chandigarh160036. India. Phone: +91-9417182983; Fax: +91-172-2690585;

Email: jsjagsingh@gmail.com 
The establishment of heterochromatin in fission yeast involves methyltransferase Clr4mediated H3-Lys9 methylation, which is bound specifically by Swi6/HP1. However, the mechanism of propagation of heterochromatin through multiple cell divisions is not known. A role of DNA replication in propagating the heterochromatin is envisaged. Studies in $S$. pombe have indicated a direct interaction between DNA Pol $\alpha$ and Swi6/HP1 and between DNA Pole and Rik1-Dos2 complex, suggesting a coupling between DNA replication and heterochromatin assembly. Here, we show that like DNA Pol $\alpha$, Pol $\delta$, which plays a role in both leading and lagging strand replication, also plays a role in silencing at mating type and centromere. We show that both the polymerases $\alpha$ and $\delta$ interact directly with both CIr4 and Swi6/HP1. Mutations in both the polymerases lead to decrease in H3-Lys9 methylation and Swi6 at the mating type and left outer repeats of centromeres I and II, with a reciprocal increase in their level at the central element, cnt, at all the three centromeres. These mutations also cause defects in chromosome segregation, recruitment of Cohesin and chromosome dynamics during mitosis and meiosis. Thus, our results indicate that a tight coordination between DNA replication machinery and propagation of the heterochromatin-specific epigenetic mark. 
Propagation of state/s of expression of genes through multiple cell divisions underlies the process of differentiation and development in all eukaryotes, including the unicellular eukaryotes, like the budding and fission yeasts, Drosophila, mouse and humans. Notable insights in recent years have revealed that more than DNA, it is the chromatin structure which functions as a Mendelian unit of inheritance (1). In an elegant study, Grewal and Klar (2) showed that in fission yeast two alternative epigenetic states of the mating type locus were propagated through not only multiple mitotic divisions but segregated as alternative Mendelian alleles during meiosis. Similar findings of stable epigenetic chromosomal states have been reported in other systems (3). Subsequent work in fission yeast has revealed that while RNAi machinery is required for the establishment of silencing, the heterochromatin proteins Swi6/HP1 and the methyltransferase Clr4 are involved in spreading of the heterochromatin (4).

However, the mechanism of propagation of epigenetic states during multiple cell divisions is not well understood. Earlier studies in S. cerevisiae showed a requirement of passage through S phase for establishment of mating-type silencing (5), which were supported by later findings showing the requirement of a functional replication origin and the proteins, that assemble the Origin Recognition Complex at replication origins, in silencing (7-10). However, later, silencing was shown to occur on an artificial template without undergoing replication $(11,12)$. Further, a role of Cohesin degradation during mitosis in silencing suggests that the existence of more than one control in establishment and propagation of silencing in $S$. cerevisiae $(13,14)$.

Despite these observations, the idea that DNA replication may play a pivotal role in propagation of heterochromatin structure remains intuitively attractive because of the implicit simplicity and ability to explain the faithful assembly of heterochromatin through direct interaction between DNA replication and heterochromatin machineries. In fact, work from our laboratory and others has shown a role of DNA polymerase $\alpha$ in propagation of heterochromatin at the mating type, centromere and telomere loci through recruitment of the chromodomain protein Swi6/HP1 in $S$. pombe (15-17). Accordingly, we proposed a replication-mediated recruitment model for propagation of heterochromatin structure (15), where in the replication enzyme, DNA Pol $\alpha$, which is needed for carrying out lagging and leading strand synthesis in all eukaryotes, may recruit the chromodomain protein Swi6/HP1 coincidentally with DNA replication (15-17). In another study, interaction of Pole, 
which is also involved in DNA replication, with the Rik1-Dos2 complex, was shown to play a role in heterochromatin silencing (18). Here, we demonstrate that both DNA Pol $\alpha$ and Pol $\delta$, in addition to their role in coordinating the lagging and leading strand replication in eukaryotes, also bind to and help in recruiting the methyltransferase Clr4 and chromodomain protein Swi6/HP1 (which form the dual components of histone code involved in writing the heterochromatin specific code of H3-Lys9 methylation and reading of this code, respectively; 19) to the mating type and centromere loci. Both pol $\alpha$ and pol $\delta$ mutants are defective in silencing at the mating type and centromere loci; this effect is related to reduced localization of Swi6/HP1 and H3-Lys9 methylation at these loci. The mutants also exhibit defective chromosome cohesion due to lack of Cohesin binding, an effect related to defective recruitment of Swi6/HP1, as well as other defects like sensitivity to cold and microtubule destabilizing drug thiabendazole and aberrant chromosome segregation during mitosis and meiosis. Surprisingly, the mutants also show enhanced localization of Swi6 and H3-Lys9-Me2 at the central region, cnt, of all three centromeres in place of the centromeric histone, Cnp1/CENPA. Thus, the components of leading and lagging strand replication orchestrate fidelity of replication of heterochromatin regions through direct interaction with and recruitment of the heterochromatin proteins, thus integrating DNA replication with the processes of silencing, sister chromatid cohesion and chromosomal dynamics during mitosis and meiosis. 


\section{MATERIALS AND METHODS}

\section{Strains and media}

The list of strains is given in Table 1 (Supplementary section). Media and conditions were as described earlier (20). Most strains were grown at $25^{\circ} \mathrm{C}$. The strains used for silencing assays carried a non-switchable mat1 locus, mat1Msmto or mat1P 17::LEU2 and the donor loci mat2 and mat3, whose cis -acting repression elements REII and REIII were deleted along with insertion of ura4 and ade6 reporters, respectively, as shown in Figure 1A. The two-hybrid system was a gift of Stephen Elledge (21).

\section{Plasmid constructs}

The construct expressing MBP-tagged Pol $\alpha$ was described earlier (15). The GST-tagged Pol $\delta$ construct, pGST-pol3-N 1-211, expressing truncated pol $\delta$ gene lacking the first 211 codons cloned into pGEX4T-1, was a gift from Dr. S. MacNeill (22). To construct the plasmid expressing (His)6-tagged, clr4 gene was PCR amplified using the primers Clr4-For Bam (ATGCGGATCCTCGCCTAAACAAGAGGAGTAT) and Clr4 RevHind (ATGCAAGCTTTTAACCGAAAAGCCAG CCAC). The PCR product was cleaved with BamHI and HindIII and cloned into the vector pQE30 which was cleaved with the same enzymes. The construct to express (His)6-tagged Swi6 was prepared by amplifying the swi6 gene using the primers Swi6-N-Bam (ATGCGGATCCCAAGAAAGGAGGTGTTCG) and Swi6-C-Rev-Hind (ATGCAAGCTTATTTTCACGGAACGTTA AG). The PCR product was cleaved with BamHI and HindIII and cloned into the vector pQE30, which was cleaved with the same enzymes.

\section{Silencing assays}

Expression of ura4 reporter inserted at various heterochromatin loci in wild type and mutant strains was monitored by the serial dilution spotting assays. $5 \mu \mathrm{l}$ aliquots of 10 -fold serial dilutions of cultures of the strains were spotted on complete plates or plates lacking uracil or containing FOA. Plates were incubated at $25^{\circ} \mathrm{C}$ for $4-5$ days. Expression of the ade6 reporter inserted at the otrlR region of cenI 
was monitored by streaking the cells on YE plates and incubating at $25^{\circ} \mathrm{C}$ for $4-5$ days. While the wild type strains harbouring the ade6 locus in the repressed state at the mat or centromere loci appear red, the mutants yield white or pink colonies. For monitoring silencing in the silencer deletion background, strains were also streaked on $\mathrm{PMA}^{+}$plates (20). After growth at $25^{\circ} \mathrm{C}$ for 5 days they were either stained with iodine or their cells were examined microscopically for the haploid meiosis phenotype, which results from simultaneous expression of the Minus and Plus transcripts in the silencing mutant (20).

\section{Pull-down assays}

The GST-Clr4 fusion protein was allowed to bind to Glutathione-agarose beads (Sigma) in MTPBS buffer $\left(100 \mathrm{mM} \mathrm{Na}_{2} \mathrm{HPO}_{4}, 16 \mathrm{mM} \mathrm{NaH}_{2} \mathrm{PO}_{4}, 150 \mathrm{mM} \mathrm{NaCl}\right)$. Glutathione-agarose beads were equilibrated in MTPBS buffer before use. The fusion protein was added to the reaction mix containing $1 \mathrm{mg} / \mathrm{ml} \mathrm{BSA}, 50 \mu \mathrm{l}$ of beads $(50 \% \mathrm{v} / \mathrm{v})$ in MTPBS buffer and allowed to bind for $1 \mathrm{hr}$ at $4^{\circ} \mathrm{C}$ with gentle mixing. Reaction with GST was included as a control and the reaction with the fusion protein was set up in triplicate. After binding, the GST-Clr4 fusion protein bound beads were collected by centrifugation $(500 \mathrm{~g}$ for $10 \mathrm{sec}$ ) and washed twice with MTPBS. Following the washings, three increasing concentrations of MBP-Pola were added in addition to $1 \mathrm{mg} / \mathrm{ml}$ BSA and $1 \mathrm{X}$ binding buffer [5X binding buffer 750mM NaCl, 100mM Tris-Cl (pH 8.0), 5mM EDTA, 0.5\% Triton X-100, 5mM DTT]. The reactions were incubated by gentle mixing for 2 hours at $4^{\circ} \mathrm{C}$ followed by four washings with the wash buffer (100mM NaCl, 20mM Tris-Cl (pH 8.0), 1mM EDTA, $0.1 \%$ Triton $\mathrm{X}-100,1 \mathrm{mM}$ DTT). After washings, the beads were suspended in $1 X$ SDS loading dye. Samples were boiled for 10 minutes and resolved by SDS-PAGE along with the input material.

In other pull-down experiments, extracts were prepared from E. coli strains expressing (His)6$\mathrm{Clr} 4$ and (His) $)_{6}$ Swi6 and allowed to bind at $4^{\circ} \mathrm{C}$ overnight to Ni-NTA resin (Qiagen; binding capacity $5-10 \mathrm{mg}$ protein/ml resin), which was equilibrated with binding buffer $\left[50 \mathrm{mM} \mathrm{NaH} 2 \mathrm{PO}_{4}(\mathrm{pH}\right.$ 8.0), $300 \mathrm{mM} \mathrm{NaCl}, 10 \mathrm{mM}$ imidazole]. Washings were performed $3-4$ times with the same buffer at $4^{\circ} \mathrm{C}$ and the beads were collected by centrifugation at $500 \mathrm{~g}$ for $5 \mathrm{~min}$. Now the crude extract prepared from strains expressing GST-Pol $\delta$ or GST-Pol $\alpha$ was added to the above resin at increasing 
concentrations (from 100 to $300 \mu \mathrm{g}$ ) along with control, $1 \mathrm{mg} / \mathrm{ml}$ BSA and $1 \mathrm{X}$ binding buffer (5X binding buffer: $750 \mathrm{mM} \mathrm{NaCl}, 100 \mathrm{mM}$ Tris-Cl, $\mathrm{pH}$ 8.0, 5mM EDTA, 5mM DTT) was added, incubated at $4^{\circ} \mathrm{C}$ for 3-4 hours to overnight and then washed four times with washing buffer $(100 \mathrm{mM}$ $\mathrm{NaCl}, 20 \mathrm{mM}$ Tris $-\mathrm{Cl}, 1 \mathrm{mM}$ EDTA, 1mM DTT). To the above samples $1 \mathrm{X}$ SDS loading buffer was added and samples boiled for 5-10 min. The samples were subjected to SDS-PAGE, Western blotted and probed with anti GST antibody.

\section{Chromatin Immunoprecipitation (ChIP) assay}

ChIP assay was performed as described earlier (23). The following oligos were used for PCR: ura4F: gaggggatgaaaaatcccat; ura4R: ttcgacaacaggattacgacc; ade6F: tgcgatgcacctgaccaggaaagt; ade6R: agagttgggtgttgatttcgctga;act1F: tcctacgttggtgatgaagc; act1R: tccgatagtgataacttgac; dhFor: ggagttgcgcaaacgaagtt; dhRev: ctcactcaagtccaatcgca. PCR conditions were: $95^{\circ} \mathrm{C}, 2 \mathrm{~min} ; 30$ cycles of $95^{\circ} \mathrm{C}, 1 \mathrm{~min}-55^{\circ} \mathrm{C}$, sec- $72^{\circ} \mathrm{C} 2 \min ; 72^{\circ} \mathrm{C}, 10 \mathrm{~min} .0 .1 \mu \mathrm{Ci}$ of $\left(\alpha^{32}-\right.$ P)-dCTP was included during PCR and the PCR products were resolved by polyacrylamide gel electrophoresis, followed by quantitation with BioRad phosphoimager.

\section{Confocal microscopy}

Sporulating asci and vegetative cells were stained with the nuclear stain 4', 6'-diamidino-2phenylindole (DAPI) to visualise the meiotic and/or mitotic division defects in swi7H4 and $\delta$ ts mutants. The 10X DAPI stock was diluted with glycerol to $4 \mathrm{X}$ just prior to use. For studying the meiotic defects, cells were plated on $\mathrm{PMA}^{+}$plates and were grown for 3-4 days at $25^{\circ} \mathrm{C}$ to allow an adequate level of sporulation. Sporulating asci were scraped off the plate and suspended in 1X PBS. The cells or spores were fixed by mixed aldehyde method (Paul Nurse's lab protocols: 'Fission Yeast Handbook'), which involves the addition of fresh $37 \%$ paraformaldehyde solution to a final concentration of $3.7 \%$, followed by the addition of glutaraldehyde to $0.2 \%$ final concentration. Fixation was allowed to proceed for 60-90 min at RT with gentle shaking. After fixation, cells and asci were collected by centrifugation, washed thrice with $1 \mathrm{X}$ PBS, followed by resuspension in PBS$\mathrm{T}$ (PBS + Triton X-100). After $30 \mathrm{sec}$ in PBS-T, cells were washed thrice in 1X PBS. After the final wash, cells were resuspended in $100-150 \mu 1$ X PBS. $6 \mu$ of this cell suspension was mixed with $4 \mu \mathrm{l}$ 
bioRxiv preprint doi: https://doi.org/10.1101/2020.10.21.349183; this version posted October 21, 2020. The copyright holder for this preprint (which was not certified by peer review) is the author/funder, who has granted bioRxiv a license to display the preprint in perpetuity. It is made available under aCC-BY-NC-ND 4.0 International license.

of $4 \mathrm{X}$ DAPI on a microscopic slide and coverslip was gently placed on the slide, pressing with a tissue paper to remove excess liquid. The samples were then visualized with a Carl Zeiss LSM 510 Meta confocal microscope.

For studying the chromosome dynamics during mitosis, vegetative cells were cultured in $5 \mathrm{ml}$ YEA (20) overnight at $25^{\circ} \mathrm{C}$. Cells were then reinoculated into $10-15 \mathrm{ml}$ fresh media (OD600 0.1-0.2) and incubated at $18^{\circ} \mathrm{C}$ with shaking till mid-log phase (OD600 0.5-0.6). Cultures were then harvested (6000 rpm for $2 \mathrm{~min}$ ). Cells were then fixed with methanol by initially resuspending in $1 \mathrm{ml}$ methanol $\left(-20^{\circ} \mathrm{C}\right)$ followed by the addition of $\sim 9 \mathrm{ml}$ chilled methanol. Cells were then kept at $-20^{\circ} \mathrm{C}$ for 10 minutes to overnight. After fixation, cells were stained with DAPI as well as with $\alpha$-tubulin antibody, TAT1 to visualize the mitotic spindle along with the nuclei.

\section{ChIP-ChIP Analysis:}

ChIP- samples used to measure the distribution of H3-K9-Me2 and Swi6 at centromeric regions according to Ekwall and Partridge (23), were processed for ChIP-on-ChIP analysis.according to Sandmann et al. (24), using Affymetrix non-redundant microarrays. 


\section{RESULTS}

\section{Mutations in Pol $\alpha$ and Pol $\delta$ abrogate silencing at the mating type and centromere loci}

To extend our earlier work showing a role of DNA Pol $\alpha$ in silencing, we checked whether DNA replication machinery, in general, is required for silencing, as it has been shown that both Pol $\alpha$ and

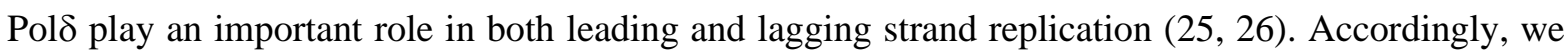
tested the effect of mutations in pol $\delta$, namely $\delta t s 1, \delta t s 2$ and $\delta t s 3$ (27) on silencing at the mating type locus. The genetic screen employed a strain in which the repression elements flanking the silent mat loci, REII flanking the mat2 locus and REIII flanking the mat3 locus (Figure 1A) were deleted along with insertion of ura4 and ade6 reporters, respectively. Earlier studies showed that mutations in swi6 and $c l r 1-c l r 4$ abrogated silencing strongly when combined with deletion of the repression elements $(28,29)$. Mutations in pola (swi7H4) and pold increased expression of the ade6 reporter flanking the mat3 locus, as indicated by growth of light pink colonies instead of the red colonies of the parent strain, which is indicative of loss of repression in the mutant (Figure 1B). Further, as shown earlier in case of the pola mutant swi7H4 (15), $\delta t s 2$ mutant showed similar loss of silencing of the mat $2 P$ locus, as indicated by iodine staining of the colonies (15; see Materials and Methods; Figure 1C). Interestingly, like swi7H4/pol $\alpha$ mutant (16), polots2 mutant also exhibited two epigenetic states that give light (L) and dark (D) staining with iodine, representing the repressed and derepressed state of the mat $2 P$ locus, respectively (Figure $1 \mathrm{C}$ ). These states also show, respectively, low and high level of the expression of the mat $2 P$-linked $u r a 4$ reporter, as indicated by level of growth on plates lacking uracil (Figure 1D). These results indicate that like Pol $\alpha$ (15-17), Pol $\delta$ is also involved in the same pathway of silencing as Swi6 and Clr1-Clr4 and plays a role in the establishment of the repressed state.

We showed earlier that swi7H4/pola mutation also abrogated silencing at the centromere loci. Therefore, we tested the effect of $\delta t s 1-\delta t s 3$ mutations on silencing at the centromere loci by monitoring the expression of the ura4 reporter inserted at the cntl and imrl regions and the ade 6 reporter at the outer repeat $\operatorname{otrlR}$ (Figure 1E). Results showed that the mutations did not affect silencing at the cnt 1 and $i m r 1 L$ region (not shown). On the other hand, silencing of the ade6 reporter inserted at the $\operatorname{otr} 1 R$ repeat was abrogated, as indicated by growth of pink and white colonies (10-34\% 
of total colonies) in all the pol $\delta$ mutants as compared to red colonies in wt strain on adenine limiting media (Figure 1F). However, unlike the pol $\alpha(15,17)$ there was no effect of pol $\delta$ mutations on silencing at the telomere loci (not shown).

\section{Reduced heterochromatin localization of Swi6/HP1 and H3-Lys9 methylation in pol $\alpha$ and pol $\delta$ mutants}

As silencing is associated with localization of Swi6 and H3-Lys9-Me2 to heterochromatin loci, we checked the localization of Swi6 and H3-Lys9-Me2 to the mat and cen loci by Chromatin immunoprecipitation (ChIP) assay. Results showed that localization of Swi6 as well as H3-Lys9 methylation was drastically reduced at the ura4 reporter flanking the mat 2 and ade6 reporter flanking otrlR repeat of cenI in both swi7H4/pola and $\delta t s 2$ mutants (Figure $1 \mathrm{G}, 1 \mathrm{H}$ ). These results were paralleled by those of ChIP-on-ChIP experiment, wherein, especially the left otrl regions of chrI and chrII showed a similar reduction in the level of H3-Lys9-Me2 and Swi6 (Figure 2, double vertical arrow heads; Supplementary Figures 1 and 2)

Surprisingly, results of ChIP-on-ChIP also revealed an enhanced localization of both Swi6 and H3-Lys9-me2 at the cnt region of Chromosome I (Figure 2) as well as chrII (Supplementary Figure 1) and chrIII (Supplementary Figure 2), which is normally occupied by the centromere-specific histone H3 variant, cnpl/CENPA..

Earlier work showed that GFP-tagged Swi6 is localized at mainly three foci, representing the heterochromatin regions, in majority of cells (30). In fact, swi7H4/pola as well as swi7-1 mutations were shown to cause delocalization of GFP-tagged Swi6 $(15,17)$. Therefore, we determined the localization of Swi6 in pol $\delta$ mutants by confocal microscopy. Results showed that, as shown in swi7H4/pol $\alpha$ mutant earlier (15), the distribution of GFP-Swi6 was drastically reduced in pold mutants, with a larger percentage of cells having only one or two foci. (Supplementary Figure 3A).

Silencing proteins like Swi6 have also been shown to be required for microtubule stability. Thus, swi6 mutant exhibits enhanced sensitivity to cold $\left(18-20^{\circ} \mathrm{C}\right)$ and the microtubule destabilizing drug, thiabendazole $(30,31)$. We tested the same properties in case of swi7H4/pol $\alpha$ and $\delta t s 1-\delta t s 3$ mutants. Interestingly, all the mutants show a level of sensitivity to cold and thiabendazole similar to that observed with swi6 mutant (Supplementary Figure 3B). Thus, both the polymerases also promote 
the mitotic microtubule stability and fidelity of chromosome segregation, which may be ascribed to their role in recruitment of Swi6 and H3-Lys9-Me2.

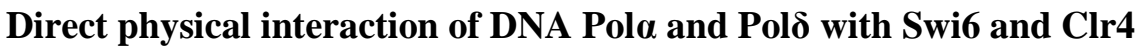

The above results suggested the possibility that Pol $\alpha$ and Pol $\delta$ may interact with Swi6 and/or Clr4. Earlier work had shown that Pol $\alpha$ binds to Swi6 in vitro and in vivo $(15,17)$. We carried out pull-down assay to determine the binding of GST-tagged Clr4 to MBP-tagged Pola. Results showed that GSTClr4 was retained by amylose beads to which MBP-Pol $\alpha$ was bound (Figure 3A, lanes 3-5) but not to beads on which MBP was immobilized (Figure 3A, lane 7). It was shown earlier that mutant Pol $\alpha$ does not interact with Swi6 in vitro $(15,17)$. Pull-down experiment using extracts from wt and swi7H4 mutant cells showed that interaction of mutant Pol $\alpha$ with Clr4 was at least 3-fold lower than that observed with wt Pola (Figure 3B). Furthermore, results of 2-hybrid experiment, supported the possibility of interaction of Pol $\alpha$ with Clr4 in vivo (Figure 3C, 3D)

We further checked whether Swi6 and or Clr4 bind to Pol $\delta$ as well. Results of pull-down assay revealed that GST-tagged Polס (Figure 4A, lanes 3-5), but not GST (Figure 4A, lane 8), could be specifically retained on the Ni-NTA beads on which (His)6-tagged Swi6 (Figure 4A, lanes 3-5) as well as (His)6-tagged Clr4 was immobilized (Figure 4B, lanes 3-5; lane 8). Furthermore, antibodies against myc epitope and Swi6 could coimmunoprecipitate Swi6 along with myc-tagged Pol $\delta$ in wt but not in swi6 4 strain (Figure 4C). Thus, Pol $\alpha$ and Pol $\delta$ bind to both Swi6 and Clr4 in vitro and in vivo and the inability of pol $\alpha$ (and possibly pold) mutant proteins to recruit Swi6 and H3-Lys9 methylation may be correlated with their reduced binding to Swi6 and Clr4.

\section{Abrogation of Cohesin binding, sister chromatid cohesion and microtubule stability in pola and} pol $\delta$ mutants

In addition to the effect on silencing, Swi6/HP1 has also been shown to be necessary for recruitment of Cohesin to the centromere and mating type loci $(32,33)$ and thus instrumental in enhancing the stability of chromosomes and facilitating faithful chromosome segregation. Since swi6 mutant has been shown to be defective in sister chromatid cohesion due to lack of recruitment of Cohesin, we tested the phenotypes of swi7H4/pol $\alpha$ and $\delta t s 1-\delta t s 3$ mutants, both of which are defective 
in Swi6 recruitment. Sister chromatid cohesion can be monitored microscopically with the help of a strain system harboring LacI-GFP fusion protein and containing the LacO DNA repeat inserted at the lys 1 locus linked to centromere 1 (cen1-GFP) (34). The binding of the GFP-tagged repressor to the repeats appears in the form of one single dot in G2 cells representing the two sister chromatids being held tightly together at the centromere region (34). Thus, nearly all wild type cells show one spot of GFP, while swi7H4, $\delta t$ s mutants show a high fraction of cells (9- 27\%) having two GFP spots, indicating a loss of sister chromatid cohesion in the mutants (Supplementary Figure 4A).

To directly check whether the binding of cohesin to the centromere loci was affected, we carried out ChIP assay. Results of ChIP analysis with strains carrying HA-tagged copy of the Rad21 subunit of cohesin showed that localization of $\operatorname{Rad} 21$, which is highly enriched in the $d h$ repeats in the otrlR region $(32,33)$, is severely abrogated in swi7H4/pola and $\delta t s 2$ mutants (Supplementary Figure 4B).

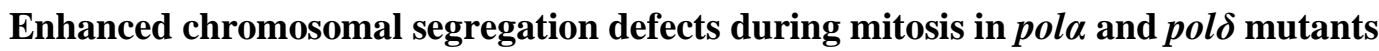

Proper assembly of heterochromatin has been shown to be important not only for silencing but also for chromosome segregation. Microscopic examination of mitotic nuclei has shown that while in wild type the two daughter nuclei of equal sizes segregate in an equidistant fashion among the presumptive daughter cell halves during cell division, the mutants defective in silencing, like swi6, clr4 and rikl, show aberrant segregation of daughter nuclei. Pidoux et al. (35) had classified the various types of lagging chromosome segregation defects. As we analyzed only fixed cells not live cells as in case of Pidoux et al. (35), for convenience, we have redefined the classes of defects based on but slightly differently from ref 33. Following detailed observation of dividing cells of swi7H4/pola and $\delta t s 1-\delta t s 3$ mutants, we identified various types of segregation defects (Figure 5A and 5B). Results show that all the pol $\delta$ mutants exhibit the lagging chromosome phenotype (class I): while $\delta t s 1, \delta t s 3$ and swi7H4 show the lagging chromosome phenotype with a chromatid being unable to catch up with the daughter nucleus (class II; Figure 5A), class II defect of lagging chromosomes in the context of uneven segregation was observed in $\delta t s 3$ and swi $7 H 4$ mutants. A grossly defective segregation resulting in fragmented nuclei (class V) was observed in $\delta t s 2$ and $\delta t s 3$ mutants, while unequal movement of daughter nuclei towards the poles (class VI) was observed only in $\delta t s 2$ mutant (Figure 5A). The total percentage of cells showing aberrant segregation defects is depicted in Figure 5B. Thus, both pola and 
bioRxiv preprint doi: https://doi.org/10.1101/2020.10.21.349183; this version posted October 21, 2020. The copyright holder for this preprint (which was not certified by peer review) is the author/funder, who has granted bioRxiv a license to display the preprint in perpetuity. It is made available under aCC-BY-NC-ND 4.0 International license.

pol $\delta$ mutants exhibit gross chromosomal segregation defects, that are reminiscent of those exhibited by swi6 mutant (33). It is noteworthy that microtubule integrity is also severely compromised in the mutants showing discontinuous, fragmented and punctate pattern, unlike a straight, uninterrupted pattern observed in wild type cells (Figure 5A).

\section{Defects in meiotic chromosome segregation}

Because proper chromatin compaction may be important for chromosome segregation during meiosis as well we checked whether Pol $\alpha$ and Pol $\delta$, which have been shown above to be important for chromosome segregation during mitosis, are also required for proper chromosome segregation during meiosis. Therefore, we analyzed the phenotypes of 4-spored zygotic asci by monitoring their staining with DAPI to assess the segregation of DNA among the asci. Based on the different staining patterns, our results indicate that while the wild type asci show proper segregation of DAPI staining among all the four ascospores in all the asci, the mutants show reduced fidelity of segregation, with the defect being primarily at the second meiotic stage (Supplementary Figure 5). 


\section{DISCUSSION}

\section{A model for chromatin replication}

In this study we have investigated a model for chromatin replication. We propose that DNA replication machinery may play an active role in replication of heterochromatin by virtue of direct interaction and recruitment of histone methyltransferase Clr4 and heterochromatin protein Swi6/HP1 on a replicating chromatin template. Our results show that indeed both DNA Pol $\alpha$ and Pol $\delta$, the key enzymes involved in lagging and leading strand replication in all eukaryotes (25), bind to both Swi6/HP1 and Clr4 and are thus required for establishing the heterochromatin-specific histone modification code, i.e., methylation of histone H3 at Lys 9 position. This modification has been shown to be generally specific for heterochromatin regions, in contrast to enrichment of H3-Lys4 methylation in euchromatin regions, in not only in fission yeast but also higher eukaryotes $(35,36)$. Histone H3 methylated at Lys9 is specifically bound by the chromodomain motif of Swi6/HP1 (37), a function again conserved during evolution. We speculate that the major components of DNA replication, namely DNA Pol $\alpha$ and Pol $\delta$ may recruit Swi6 and Clr4 on the replicating heterochromatin template and coordinate their cooperative actions- histone H3-Lys9 methylation, followed by binding by Swi6. Because of binding between Swi6 and Clr4, the process of methylation and binding by Swi6 may become highly cooperative and dynamic, leading to efficient duplication of the parental heterochromatin protein complement in the daughter chromatids. The coupling to the process of replication may have additional significance: the processive nature of replication may facilitate a rapid process of assembly of chromatin and ensure precision of duplication of the chromatin template in coordination with the $\mathrm{S}$ phase during cell cycle. Further, since the mechanism of replication, involving a coordinated function of DNA polymerases $\alpha$ and $\delta$ and other replication proteins and the proteins involved in heterochromatin assembly, is conserved during evolution, our model, suggesting a direct coupling of DNA replication machinery with active recruitment of heterochromatin proteins may also be conserved.

Consistent with this view, various findings in other organisms have highlighted the role of DNA replication components in silencing. For example, mutations in ORC suppress position-effect variegation (a hallmark of silenced regions wherein genes inserted near to silenced regions exhibit variegated expression patterns) in Drosophila (38). Mutations that disrupt silencing at rDNA and 
telomeres have been identified in DNA replication proteins and DNA-replication-related proteins such as DNA helicase Dna2p, PCNA loading factor Rfc1p $(39,40)$. Also, mutations potentially suppressing silencing defects are found in DNA replication proteins including DNA Pole (41), the replication initiation factor Cdc45, PCNA and RF-C (42). Mutations in DNA Pol $\alpha$ have also been shown to disrupt rDNA silencing and telomere-position effects in $S$. cerevisiae $(43,44)$. The DNA replication-linked histone deposition factor, CAF1 (Chromatin Assembly Factor I) assembles histones specifically onto replicated DNA molecules via binding of the CAF1 p150 subunit to PCNA (44). Mutant forms of PCNA defective in CAF1 interaction are also defective in establishing silencing (45), suggesting that CAF1 and PCNA link DNA replication to chromatin assembly and silencing. Mutations in CAF1 and another chromatin assembly factor ASF1 also disrupt silencing (46,47). Mammalian CAF1 p150 subunit directly binds HP1 (48). PCNA associates with HDAC activity in human cells, strengthening the role of PCNA as a factor coordinating DNA replication and epigenetic inheritance (49). Recently, it has been shown that the methyl-CpG binding protein MBD1 couples histone H3 Lys9 methylation by SETDB1 to DNA replication and chromatin assembly (50).

Another important factor in coordinating DNA replication and heterochromatin assembly is the interaction between Swi6 and Clr4, as reported earlier (51), similar to interaction between mammalian Suv39H1 and mouse HP1 (52). Furthermore, genetic and molecular studies in S. pombe have shown a tightly coordinated spreading of Swi6 and the H3-Lys9-Me2 across the $K$ region of mating type locus (53). In mammalian systems, co-localization and co-immunoprecipitation studies suggested an interaction between SUV39H1 and HP1 (54).A recent study analysed the interrelationships between histone $\mathrm{H} 3-\mathrm{K} 9$ methylation, transcriptional repression and HP1 recruitment and showed that targeting HP1 to chromatin required not only H3-K9 methylation but also a direct protein-protein interaction between Suv39H1 and HP1, underlining the importance of Swi6-Clr4 interaction in establishing heterochromatin states (55).

These studies, together with our results moot the question whether like replication, the process of heterochromatin replication is also semiconservative with the components of heterochromatin, like Swi6 and Clr4 segregating in a semi-conservative manner coincidentally with DNA replication. In a pertinent report Tagami et al showed that CAF1 forms a complex with a heterodimer of $\mathrm{H} 3-\mathrm{H} 4$ rather than the $\mathrm{H} 3-\mathrm{H} 4$ tertramer, thus suggesting the possibility that $\mathrm{H} 3-\mathrm{H} 4$ dimer may be deposited at a replicating template, subsequent to segregation of two H3-H4 dimer 
halves along the segregating chromatids (56). Thus, the present results suggest that the Clr4-Swi6 complex may together be recruited by the DNA polymerases and help in carrying out a chromatin template-dependent copying of the H3-Lys9 methylation mark-coupled to Swi6 binding on the daughter chromatids in a highly processive manner. The nascent assembly of nucleosomes is executed by CAF1 (57). Since CAF1 also binds HP1 (58), Swi6 deposition may start with CAF1. Likewise, the binding of Swi6 to CAF1 (and Pol $\alpha$ ) may involve the chromoshadow domain of Swi6 and MOD1-interacting region (MIR; 59), which is present in CAF1 (59), Pol $\alpha$ (17) and TIF1- $\alpha$ and TIF1- $\beta$ (60; sequences similar to MIR are also found in Pol $\delta$ ). Once Swi6 is recruited, the Clr4 associated with it may bring about H3-Lys9 methylation and through positive feedback loop involving the interaction with Swi6, spread the region of heterochromatin in a catalytic and highly cooperative manner. Importantly, the interaction with DNA Polymerases would make the process of reassembly of heterochromatin highly cooperative and fast, which is important considering the narrow time window available for replication of heterochromatin region in $S$. pombe and metazonas, in general. In agreement, we find nearly 3 -fold increase in the ratio of Swi6 to Pol $\alpha$ during $S$ phase, coinciding with the timing when heterochromatin region is replicated $(61,62$; Balveer Singh, unpublished data). It would be interesting to study the role of DNA replication machinery vis-à-vis the chromatin assembly factor CAF1 in recruitment of Swi6 and Clr4.

However, these findings are difficult to reconcile with the results from budding yeast showing that silencing could be established on circular DNA molecules containing the mating type locus in the absence of DNA replication although, notably, passage through $\mathrm{S}$ phase was still essential $(11,12)$. Since presence of the cis-acting silencer has been shown to be continuously required for heterochromatin in the budding yeast (63), some molecular event during S phase that recruits the heterochromatin protein Sir1 to the cis -acting silencer may substitute the process of replication. Alternatively, the mechanisms of silencing in the budding and fission yeast may be fundamentally different.

It remains to be seen whether, apart from Swi6 and Clr4, other silencing factors are also associated with DNA polymerases. Our preliminary results indicate a genetic interaction of pola/swi7H4 mutant with all the silencing mutants clrl-clr4 and swi6. Homothallic switching strains of these mutants as well as swi7H4 mutant show nearly normal iodine staining as well as the level of 
switching, as measured by the percentage of zygotic asci, double mutants with swi7H4 showed a drastic decrease in the level of sporulation as well as iodine staining (Supplementary Figure 6). These results suggest that together with Pol $\alpha$, the heterochromatin proteins may play a synergistic role in mating type switching as well.

\section{A role of DNA replication machinery in sister chromatid cohesion}

It is also interesting to note that the heterochromatin protein assembly is coupled to replication on one hand and to the process of cohesion between sister chromatids on the other, which, in turn, ensures stable higher order organization, integrity of chromosomes and their faithful segregation during mitosis and meiosis. Our results suggest that DNA replication is also integrated to the latter processes possibly through its role in heterochromatin assembly. The process of DNA replication being processive, the heterochromatin assembly can be executed with high fidelity and speed, which in turn may recruit Cohesin in a highly cooperative manner. Accordingly, the process of chromatin assembly with cohesion being recruited both along the leading and lagging strand templates, can ensure a duplicative recruitment of Cohesin on both the daughter chromatids. This view is consistent with a recent report (64), which suggests recruitment of two separate cohesion complexes on the daughter chromatids. This speculative scenario is visualized in Figure 7. Consequently, in the replication mutants even a slightly reduced binding to the heterochromatin components may elicit severe consequences including defects not only in silencing, which is a functional correlate of the heterochromatin, but also in the reproduction of higher order chromosome structure and recruitment of Cohesin, leading to enhanced chromosome loss, chromatid segregation defects, aneuploidy and loss of viability. Thus, our studies indicate a coordination and integration of the process of DNA replication with heterochromatin assembly as well as sister chromatid cohesion. Because of the conservation of these machineries during evolution, eukaryotic species may have a highly conserved system of spatio-temporal coordination of the replication machinery with heterochromatin assembly and sister chromatid cohesion. Any defects in these steps may lead to aberrant chromosome segregation eliciting disease states including cancer. 


\section{REFERENCES}

1. Klar, A.J. (1998) Propagating epigenetic states through meiosis: where Mendel's gene is more than a DNA moiety.Trends Genet., 14, 299-301.

2. Grewal, S.I. and Klar, A.J. (1996) Chromosomal inheritance of epigenetic states in fission yeast during mitosis and meiosis. Cell, 86, 95-101.

3. Cavalli, G. and Paro, R. (1999) Epigenetic inheritance of active chromatin after removal of the main transactivator. Science, 286, 955-958.

4. Hall, I. M., Shankaranarayana, G. D., Noma, K., Ayoub, N., Cohen, A., and Grewal, S. I. (2002) Establishment and maintenance of a heterochromatin domain. Science, 297, 22322237.

5. Miller, A. M. and Nasmyth, K. A. (1984) Role of DNA replication in the repression of silent mating type loci in yeast. Nature, 312, 247-251.

6. Rivier, D. H., and Rine, J. (1992) An origin of DNA replication and a transcription silencer require a common element. Science, 256, 659-663.

7. Bell, S. P., Kobayashi, R. and Stillman, B. (1993) Yeast origin recognition complex functions in transcription silencing and DNA replication. Science, 262, 1844-1849.

8. Foss, M., McNally, F. J., Laurenson, P. and Rine, J. (1993) Origin recognition complex (ORC) in transcriptional silencing and DNA replication in Saccharomyces cerevisiae. Science, 262, 1838-1844.

9. Li, J. J. and Herskowitz, I. (1993) Isolation of. ORC6, a component of the yeast origin recognition complex by a one-hybrid system. Science, 262, 1870-1874. 
10. Micklem, G., Rowley, A., Harwood, J., Nasmyth, K., and Diffley, J. F. (1993) Yeast origin recognition complex is involved in DNA replication and transcriptional silencing. Nature, 366, 87-89.

11. Kirchmaier, A. L. and Rine, J. (2001) DNA replication-independent silencing in S. cerevisiae. Science, 291, 646-650.

12. Li, Y. C., Cheng, T. H. and Gartenberg, M. R. (2001) Establishment of transcriptional silencing in the absence of DNA replication. Science, 291, 650-653.

13. Kirchmaier, A. L. and Rine, J. (2006) Cell Cycle Requirements in Assembling Silent Chromatin in Saccharomyces cerevisiae. Mol. Cell Biol., 26, 852-862.

14. Lau, A., Blitzblau, H. and Bell, S. P. (2002) Cell-cycle control of the establishment of mating-type silencing in S. cerevisiae. Genes Dev., 16, 2935-2945.

15. Ahmed, S., Saini, S., Arora, S. and Singh, J. (2001) Chromodomain protein Swi6mediated role of DNA polymerase $\alpha$ in establishment of silencing in fission yeast. J. Biol. Chem., 276, 47814-47821.

16. Ahmed, S. and Singh, J. (2001) An Imprinting Function of DNA polymerase $\alpha$ in Establishment of Silencing in Schizosaccharomyces pombe. Curr. Sci. (Banglore), 80, $1337-1343$.

17. Nakayama, J., Allshire, R. C., Klar, A. J. and Grewal, S. I. (2001) A role for DNA polymerase alpha in epigenetic control of transcriptional silencing in fission yeast. Embo J., 20, 2857-2866.

18. Li, F., Martienssen, R. and Cande W.Z. (2011) Coordination of DNA Replication and Histone Modification by the Rik1-Dos2 Complex. Nature, 475, 244-248.

19. Jenuwein, T. and Allis, C. D. (2001) Translating the histone code. Science, 293, 1074-1080. 
20. Moreno, S., Klar, A. and Nurse, P. (1991) Molecular genetic analysis of fission yeast Schizosaccharomyces pombe. Methods Enzymol., 194, 795-823.

21. Bai C, Elledge SJ. (1997) Gene identification using the yeast two-hybrid system. Methods Enzymol., 283,141-156.

22. MacNeill, S. A., Moreno, S., Reynolds, N., Nurse, P. and Fantes, P. A. (1996) The fission yeast $\mathrm{Cdc1}$ protein, a homologue of the small subunit of DNA polymerase delta, binds to Pol3 and Cdc27 Embo J., 15, 4613-4628.

23. Ekwall, K., and Partridge J.F. (1999) Fission yeast chromosome analysis. Fluorescence in situ hybridization (FISH) and chromatin immunoprecipitation (ChIP). In Chromosome Structural Analysis: a Practical Approach (ed. W.A. Bickmore), Oxford University Press Oxford, UK W.A. Bickmore, 38-57.

24. Sandmann, T., Jakobsen, J.S. and Furlong, E.E. ChIP-on-chip protocol for genome-wide analysis of transcription factor binding in Drosophila melanogaster embryos. Nat. Protocols, 1, 2839-2855.

25. Bell, S. P. and Dutta, A. (2002) DNA replication in eukaryotic cells. Ann. Rev. Biochem., 71, 333-374.

26. Johnson, R.E., Klassen, R., Prakash, L. and Prakash, S. (2015) A major role of DNA polymerase $\delta$ in replication of both the leading and lagging DNA strands. Mol. Cell, 59, $163-175$.

27. Francesconi, S., Park, H. and Wang, T. S. (1993) Fission yeast with DNA polymerase delta temperature sensitive alleles exhibits cell division cycle phenotype...Nucleic Acids Res. 21, 3821-3828., 
28. Thon, G., Cohen, A. and Klar, A. J. (1994) Three additional linkage groups that repress transcription and meiotic recombination in the mating-type region of Schizosaccharomyces pombe. Genetics, 138, 29-38.

29. Thon, G., Bjerling, K. P. and Nielsen, I. S. (1999) Localization and properties of a silencing element near the mat3-M mating-type cassette of Schizosaccharomyces pombe. Genetics, 151, 945-963.

30. Ekwall, K., Javerzat, J.P., Lorentz, A., Schmidt, H., Cranston, G. and Allshire, R. (1995) The chromodomain protein Swi6: a key component at fission yeast centromeres. Science 269, 1429-1431.

31. Ekwall, K., Nimmo, E. R., Javerzat, J. P., Borgstrom, B., Egel, R., Cranston, G. and Allshire, R. (1996) Mutations in the fission yeast silencing factors clr4+ and rik1+ disrupt the localisation of the chromo domain protein Swi6p and impair centromere function. J. Cell Sci., 109, 2637-2648.

32. Bernard, P., Maure, J. F., Partridge, J. F., Genier, S., Javerzat, J. P. and Allshire, R. C. (2001) Requirement of heterochromatin for cohesion at centromeres. Science, 294, 25392542.

33. Nonaka, N., Kitajima, T., Yokobayashi, S., Xiao, G., Yamamoto, M., Grewal, S. I. and Watanabe, Y. (2002) Recruitment of cohesin to heterochromatic regions by Swi6/HP1 in fission yeast. Nat. Cell Biol., 4, 89-93.

34. Nabeshima, K., Nakagawa, T., Straight, A. F., Murray, A., Chikashige, Y., Yamashita, Y. M., Hiraoka, Y. and Yanagida, M. (1998) Dynamics of centromeres during metaphase-anaphase transition in fission yeast: Dis1 is implicated in force balance in metaphase bipolar spindle. Mol. Biol. Cell, 9, 3211-3225. 
35. Pidoux, A. L., Uzawa, S., Perry, P. E., Cande, W. Z. and Allshire, R. C. (2000) Live analysis of lagging chromosomes during anaphase and their effect on spindle elongation rate in fission yeast. J. Cell Sci., 113, 4177-4191.

36. Elgin, S. C. and Grewal, S. I. (2003) Heterochromatin: silence is golden. Curr. Biol. 13, R895-898.

37. Bannister, A. J., Zegerman, P., Partridge, J. F., Miska, E. A., Thomas, J. O., Allshire, R. C. and Kouzarides, T. (2001) Selective recognition of methylated lysine 9 on histone H3 by the HP1 chromo domain. Nature, 410, 120-124.

38. Pak, D. T., Pflumm, M., Chesnokov, I., Huang, D. W., Kellum, R., Marr, J., Romanowski, P. and Botchan, M. R. (1997) Association of the origin recognition complex with heterochromatin and HP1 in higher eukaryotes. Cell, 91, 311-323.

39. Singer, M. S., Kahana, A., Wolf, A. J., Meisinger, L. L., Peterson, S. E., Goggin, C., Mahowald, M. and Gottschling, D. E. (1998) Identification of high-copy disruptors of telomeric silencing in Saccharomyces cerevisiae. Genetics, 150, 613-632.

40. Smith, J. S., Caputo, E. and Boeke, J. D. (1999) A genetic screen for ribosomal DNA silencing defects identifies multiple DNA replication and chromatin-modulating factors. Mol. Cell Biol., 19, 3184-3197.

41. Wang, Z., Wu, X. and Friedberg, E. C. (1993) DNA repair synthesis during base excision repair in vitro is catalyzed by DNA polymerase epsilon and is influenced by DNA polymerases alpha and delta in Saccharomyces cerevisiae. Mol. Cell Biol., 13, 1051-1058.

42. Ehrenhofer-Murray, A. E., Kamakaka, R. T. and Rine, J. (1999) A role for the replication proteins PCNA, RF-C, polymerase epsilon and Cdc45 in transcriptional silencing in Sacharomyces cerevisiae. Genetics, 153, 1171-1182. 
43. Adams Martin, A., Dionne, I., Wellinger, R. J. and Holm, C. (2000) The function of DNA polymerase alpha at telomeric $\mathrm{G}$ tails is important for telomere homeostasis Mol. Cell Biol., 20, 786-796.

44. Shibahara, K. and Stillman, B. (1999) Replication-dependent marking of DNA by PCNA facilitates CAF-1-coupled inheritance of chromatin. Cell, 96, 575-585.

45. Zhang, Z., Shibahara, K. and Stillman, B. (2000) PCNA connects DNA replication to epigenetic inheritance in yeast. Nature, 408, 221-225.

46. Enomoto, S. and Berman, J. (1998) Chromatin assembly factor I contributes to the maintenance, but not the re-establishment, of silencing at the yeast silent mating loci. Genes Dev., 12, 219-232.

47. Kaufman, P. D., Kobayashi, R. and Stillman, B. (1997) Ultraviolet radiation sensitivity and reduction of telomeric silencing in Saccharomyces cerevisiae cells lacking chromatin assembly factor-I. Genes Dev., 11, 345-357.

48. Murzina, N., Verreault, A., Laue, E. and Stillman, B. (1999) Heterochromatin dynamics in mouse cells: interaction between chromatin assembly factor 1 and HP1 proteins. Mol. Cell, 4, 529-540.

49. Milutinovic, S., Zhuang, Q. and Szyf, M. (2002) Proliferating cell nuclear antigen associates with histone deacetylase activity, integrating DNA replication and chromatin modification. J. Biol. Chem., 277, 20974-20978.

50. Sarraf, S. A. and Stancheva, I. (2004) DNA binding selectivity of MeCP2 due to a requirement for A/T sequences adjacent to methyl-CpG. Mol. Cell, 15, 595-605. 
51. Haldar, S., Saini, A., Nanda, J.S., Saini, S. and Singh, J. (2011) Role of Swi6/HP1 selfassociation-mediated recruitment of Clr4/Suv39 in establishment and maintenance of heterochromatin in fission yeast. J. Biol. Chem., 286, 9308-9320

52. Yamamoto, K. and Sonoda, M. (2003) Self-interaction of heterochromatin protein 1 is required for direct binding to histone methyltransferase, SUV39H1. Biochem. Biophys. Res. Commun., 301, 287-292.

53. Noma, K., Allis, C. D. and Grewal, S. I. (2001) Transitions in distinct histone H3 methylation patterns at the heterochromatin domain boundaries. Science, 293, 1150-1155.

54. Aagaard, L., Laible, G., Selenko, P., Schmid, M., Dorn, R., Schotta, G., Kuhfittig, S., Wolf, A., Lebersorger, A., Singh, P. B., Reuter, G. and Jenuwein, T. (1999) Functional mammalian homologues of the Drosophila PEV-modifier Su(var)3-9 encode centromereassociated proteins which complex with the heterochromatin component M31. Embo J., 18, 1923-1938.

55. Stewart, M. D., Li, J. and Wong, J. (2005) Relationship between histone H3 lysine 9 methylation, transcription repression, and heterochromatin protein 1 recruitment. Mol. Cell Biol., 25, 2525-2538.

56. Tagami, H., Ray-Gallet, D., Almouzni, G. and Nakatani, Y. (2004) Histone H3.1 and H3.3 complexes mediate nucleosome assembly pathways dependent or independent of DNA synthesis. Cell, 116, 51-61.

57. Verreault, A., Kaufman, P. D., Kobayashi, R. and Stillman, B. (1996) Nucleosome assembly by a complex of CAF-1 and acetylated histones H3/H4. Cell, 87, 95-104. 
58. Murzina, N., Verreault, A., Laue, E. and Stillman, B. (1989) Heterochromatin dynamics in mouse cells: interaction between chromatin assembly factor 1 and HP1 proteins. Mol. Cell, 4, 529-540.

59. Smothers, J, F. and Henikoff, S. (2000) The HP1 chromo shadow domain binds a consensus peptide pentamer. Curr. Biol., 10, 27-30.

60. Ryan, R. F., Schultz, D. C., Ayyanathan, K., Singh, P. B., Friedman, J. R., Fredericks, W. J. and Rauscher, F. J., III (1999) KAP-1 corepressor protein interacts and colocalizes with heterochromatic and euchromatic HP1 proteins: a potential role for Krüppel-associated box-zinc finger proteins in heterochromatin-mediated gene silencing. Mol. Cell Biol., 19, 4366-4378.

61. Nakayama, J., Klar, A. J. and Grewal, S. I. (2000) A chromodomain protein, Swi6, performs imprinting functions in fission yeast during mitosis and meiosis. Cell, 101, 307-317.

62. Choi, E. S, Shin, J. A., Kim, H.S. and Jang, Y. K. (2005) Dynamic regulation of replication independent deposition of histone H3 in fission yeast. Nucleic Acids Res., 33, 7102-7110.

63. Cheng, T. H. and Gartenberg, M. R. (2000) Yeast heterochromatin is a dynamic structure that requires silencers continuously. Genes Dev., 14, 452-463.

64. Chang, C. R., Wu, C. S., Hom, Y. and Gartenberg, M. R. (2005) Targeting of cohesin by transcriptionally silent chromatin. Genes Dev., 19, 3031-3042. 


\section{Acknowledgements}

We are grateful to Teresa Wang for the pols mutants, H. Okayama for the swi7H4 mutant, G. Thon for the strain PG1649, R. Allshire for the strains carrying ura4 and ade6 reporters at centromere, K. Ekwall for the strains HU393 and HU395, A. Pidoux for the plasmid harbouring GFP -Swi6, J.P. Javerzat for the strain harbouring HA-tagged $\operatorname{rad} 21$. M. Yanagida fro strain having HA- and GFP-tagged cnp1 and S. MacNeil for the plasmid expressing GST-tagged Polס. We thank S. Haldar and A. Sharma for reading the manuscript. This work was supported by the Intramural support from Council of Scientific and

Industrial Research (CSIR), New Delhi, India. Kamlesh Bisht and Nandni Nakwal are recipients of Senior Research Fellowship from CSIR. 


\section{FIGURE LEGENDS}

Figure 1. pol $\alpha$ and pol $\delta$ mutations abrogate silencing and localization of Swi6 and H3-Lys9 methylation at mating type and centromere loci. (A) The organization of mating type locus, depicting the active mat 1 locus and the silent loci mat2 and mat3. Sites of deletion of the cis-acting silencers REII and REIII, flanking mat 2 and mat 3 loci, respectively, are indicated by the sign. Also indicated are the insertions of ura4 near mat2 and ade6 reporter gene near the mat3 locus. (B) Both pola (swi7H4) and pol $\delta$ mutations ( $\delta t s 1-\delta t s 3)$ cause derepression of the ade6 reporter linked to mat3 locus. The colonies of the wild type and mutant strains were streaked on adenine limiting plates YE (18), and grown at $25^{\circ} \mathrm{C}$ for 4 days (top panel). (C) $\delta t s 2$ mutation causes derepression of the silent locus mat 2 having its repression element deleted ( REII ). Cells of the indicated strains were streaked on PMA plates, grown for $3-4$ days at $25^{\circ} \mathrm{C}$ and stained with iodine. Cells of dark and light staining colonies were cultured, serial dilutions spotted on complete, -ura and FOA plates and allowed to grow at $25^{\circ} \mathrm{C}$ for 3-4 days. (D) ChIP assay was performed with the strains having the REII deleted in wild type, swi7H4 and $\delta t s 2$ mutant backgrounds and enrichment of Swi6 and Lys9-methylated H3 at ura4 reporter linked to mat 2 locus versus actl as a negative control quantitated. Histogram shows the quantitation of the ChIP data representing the average of two independent experiments. (E) A schematic representation of the cenI locus, showing insertions of ura4 reporter at the cntl and imrlL loci and insertion of ade6 reporter at the outer repeat otrlR. (F) pol $\delta$ mutations derepress the ade6 reporter at the outer repeat $\operatorname{otr} 1 R$ of $c e n I$. The indicated strains were streaked on adenine-limiting plates (YE), allowed to grow at $25^{\circ} \mathrm{C}$ and photographed. The percentage of pink and white colonies

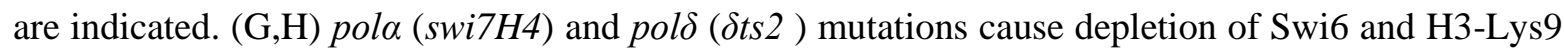
methylation at the mat2::ura4 (G) or ade 6 reporter inserted at the $\operatorname{otr} 1 R$ region of $\operatorname{chr}(\mathrm{H})$. Strains of the indicated strains were subjected to ChIP assay and enrichment of Swi6 and H3-Lys9 methylation at the ura4 for mat2-linked ura4 reporter versus act1 (G) and ade6 located at the 
heterochromatic otrlR versus the euchromatic ade6DN/N (H) quantitated by PCR. Histogram shows the quantitation of the ChIP data representing the average of two independent experiments.

Figure 2. ChIP-on-ChIP assay to quantitate the level of H3-Lys9-Me2 and Swi6 in wild type versus swi7H4/pol $\alpha$ and poldts2 mutants at the cenI. Double vertical arrows indicate the regions in the outer repeat reduction in the level of H3-Lys9-Me2 and Swi6.

Figure 3. Interaction of Clr4 with DNA Pol $\alpha$ in vitro and in vivo. (A) Pol $\alpha$ interacts with Clr4 in vitro. Pull-down assay was performed in which GST-Clr4 was immobilized on Gluthione agarose beads and increasing concentrations of MBP-Pol $\alpha$ (lanes 3-5) were bound to the beads. The bound fractions were resolved by SDS-PAGE and stained with Coomassie blue. In another control MBP was reacted with the beads to which GST-Clr4 was bound (lane 7), showing no MBP indicating lack of binding of GST-Clr4. (B) Reduced binding of mutant Pola/swi7H4 protein to Clr4 in vitro. Increasing concentrations of extracts of swi7H4 mutant cells were treated with Ni-NTA beads to which extract prepared from the E. coli strain expressing (His)6-tagged Clr4 was bound. C represents the Ni- NTA beads alone to which wt extract was bound. Wild type extract was added at the same concentration as the highest concentration of swi7H4 mutant extract $300 \mu \mathrm{g}$ ). (C, D) Two-hybrid assay showing interaction between Pol $\alpha$ and Clr4 in vivo. Shown is the ability of two hybrid system co-expressing pol $\alpha$ and $c l r 4$ to activate the expression of lacz (C) or his 3 reporter gene (D).

Figure 4. Pol $\delta$ interacts with Swi6 and Clr4 in vitro and in vivo. (A) Pull-down assay was performed by binding increasing concentrations of GST-Pol $\delta$ to Ni-NTA resin on which (His) ${ }_{6}$-tagged Swi6 was immobilized (lanes 3-5). The control represents Ni-NTA column alone (lane 6). Lanes 1 and 2 represent the loading controls of (His) 6-Swi6 and GST-Pold, respectively. As controls, binding of GST alone (lane 7) to Ni-NTA beads was tested (lane 8). (B) Pull-down assay was performed by 
binding increasing concentrations of GST-Pol $\delta$ to Ni-NTA resin on which (His)6-tagged Clr4 was immobilized (lanes 3-5). The control represents Ni-NTAcolumn alone (lane 6). Lanes 1 and 2 represent the loading controls of (His)6-Clr4 and GST-Pold, respectively. As controls, binding of GST alone (lane 7) to Ni-NTA beads was tested (lane 8). The bound fractions were resolved by SDS-PAGE and immunoblotted with anti-GST antibody. (C) Interaction of Pol $\delta$ with Swi6 in vivo. Extracts from untagged and pols-myc tagged in $s w i 6^{+}$or swi $6 \Delta$ background were immunoprepitated followed by western blotting with anti-myc and Swi6 atnibodies.

Figure 5. Chromosome segregation defects during mitosis in pol $\alpha$ and pol $\delta$ mutants. (A) Log phase

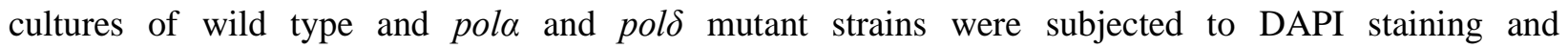
immunofluorescence microscopy using anti $\alpha$-tubulin antibody. Representative images of the cells showing staining with anti $\alpha$-tubulin antibody and DAPI and their overlaps are shown. Various classes of segregation defects shown by the mutants based on supplementary Fig. 2 are shown. (B) Histogram showing the quantitation of the aberrant segregation defects. In each case at least a total of 200 dividing cells were counted.

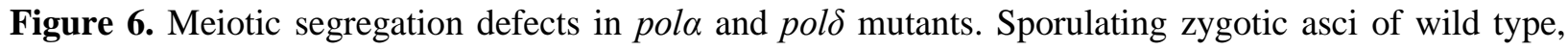

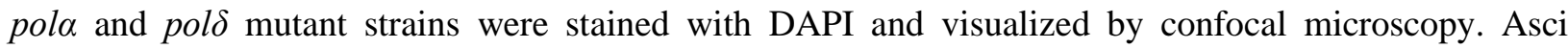
showing differential DAPI staining of zygotic ascospores were counted among a total of 200 asci and tabulated.

Figure 7. Chromatin replication model. A speculative model depicting the coupling of DNA replication machinery comprising of DNA Pol $\alpha$ and Pol $\delta$ to heterochromatin proteins Swi6/HP1 and Clr4, and through Swi6, with cohesion, thus bringing about a replication assisted duplication of the epigenetic information of heterochromatin and sister chromatid cohesion. 
A

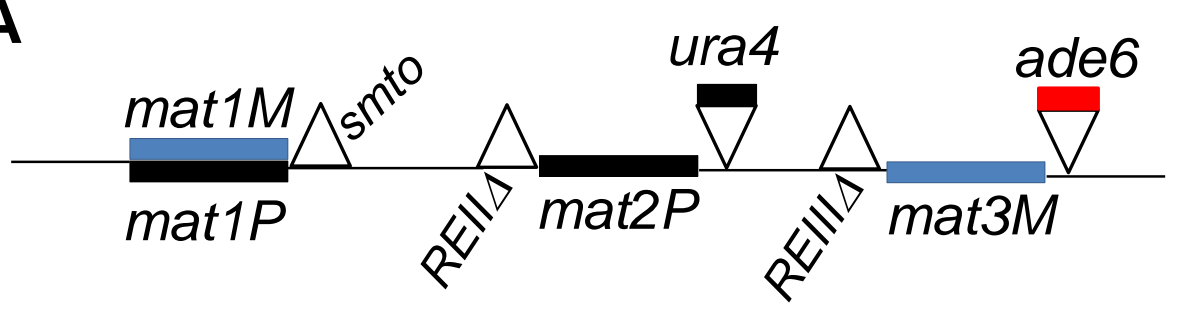

B

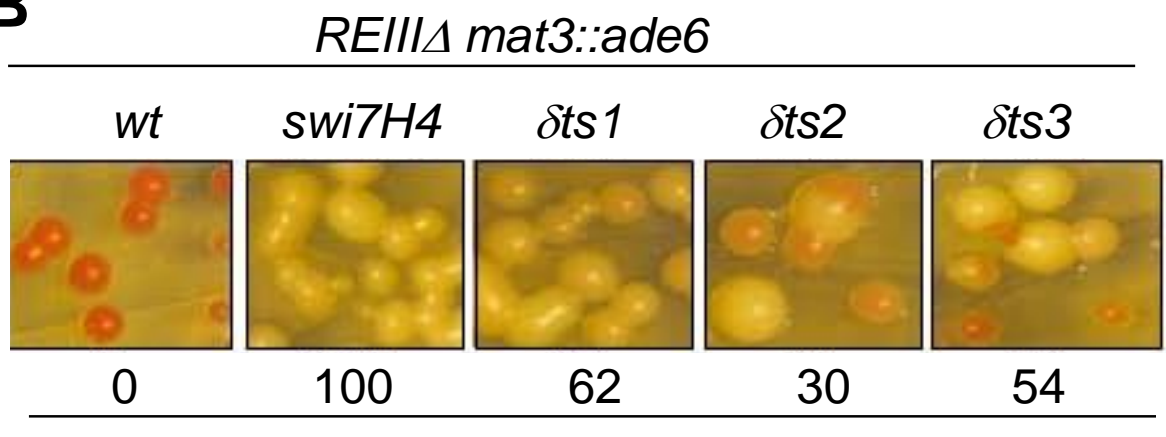

$\%$ white/pink colonies

C

mat1Msmto REIIA mat2::ura4

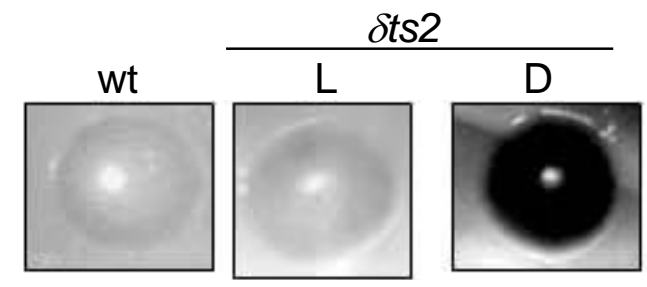

D

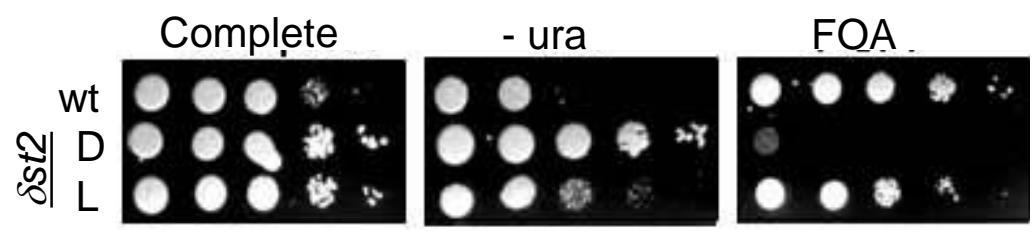

G

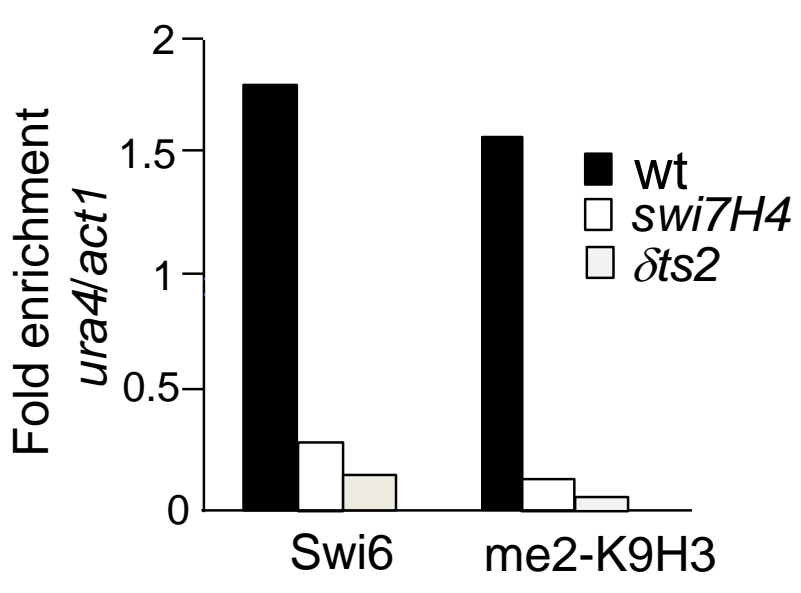

$\mathbf{E}$

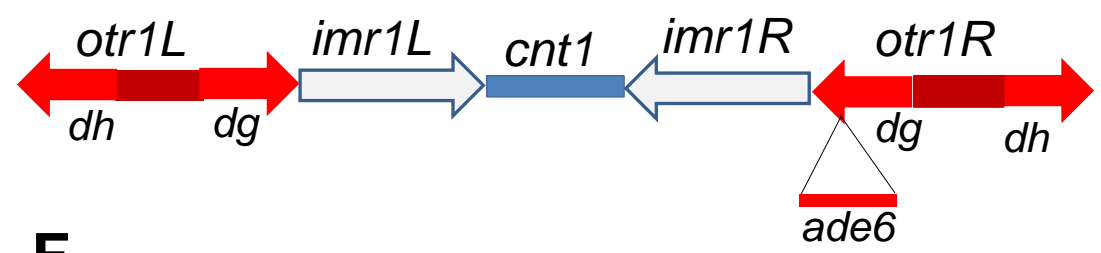

$\mathbf{F}$ otr1R::ade6

\begin{tabular}{|c|c|c|c|c|}
\hline$w t$ & $\delta t s 1$ & $\delta t s 2$ & dts3 & swi7H4 \\
\hline$<$ & & & & \\
\hline 3 & 10.3 & 31.8 & 8.5 & 100 \\
\hline
\end{tabular}

$\%$ white/pink colonies

H
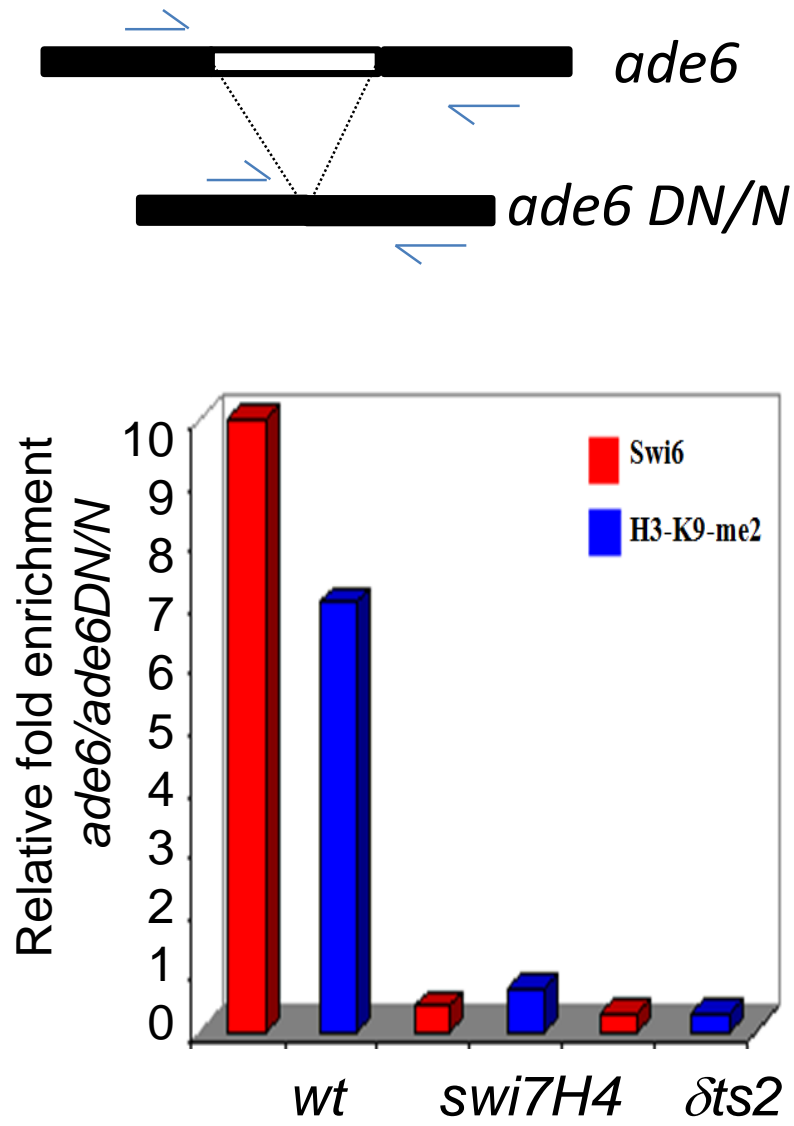


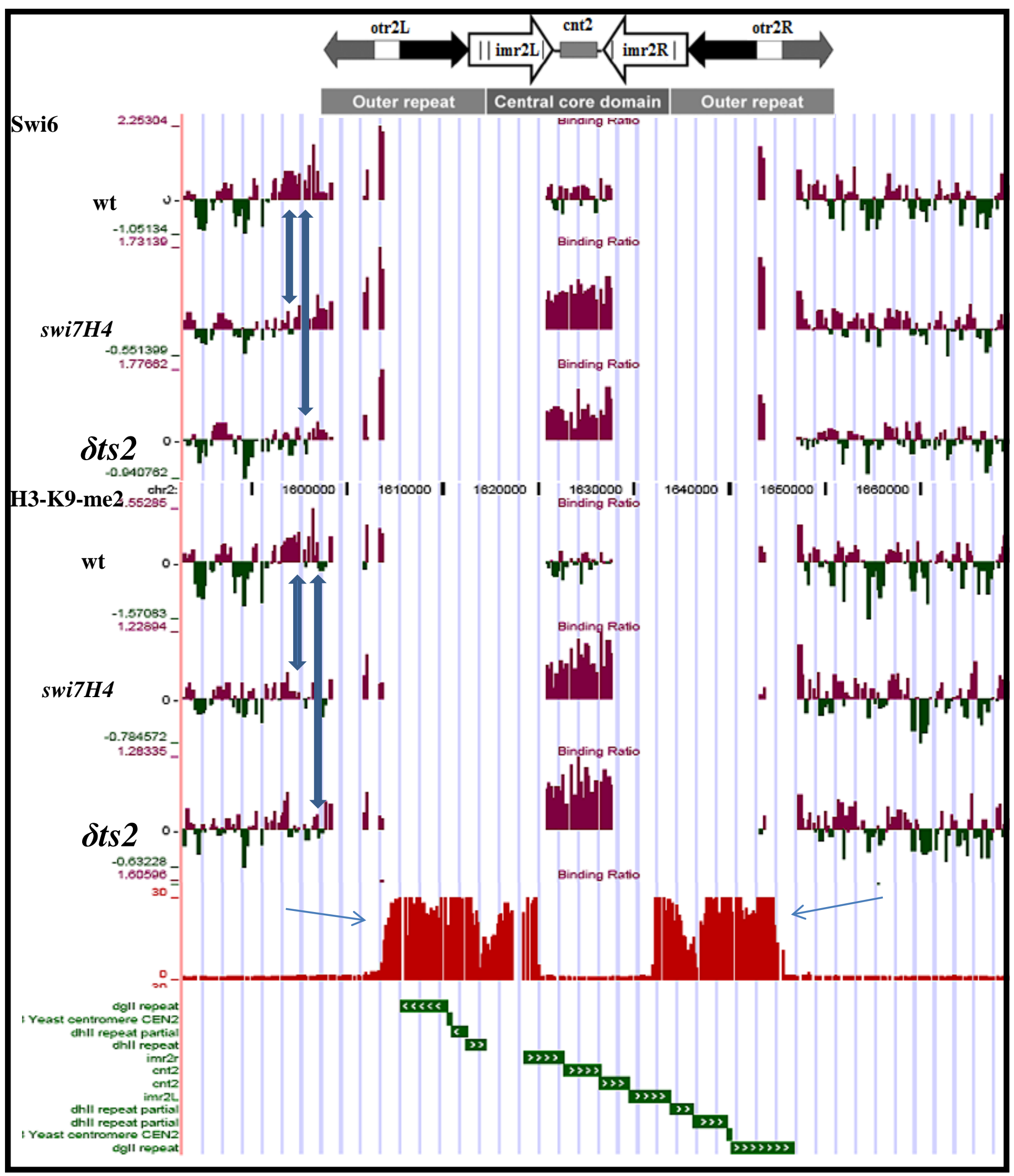




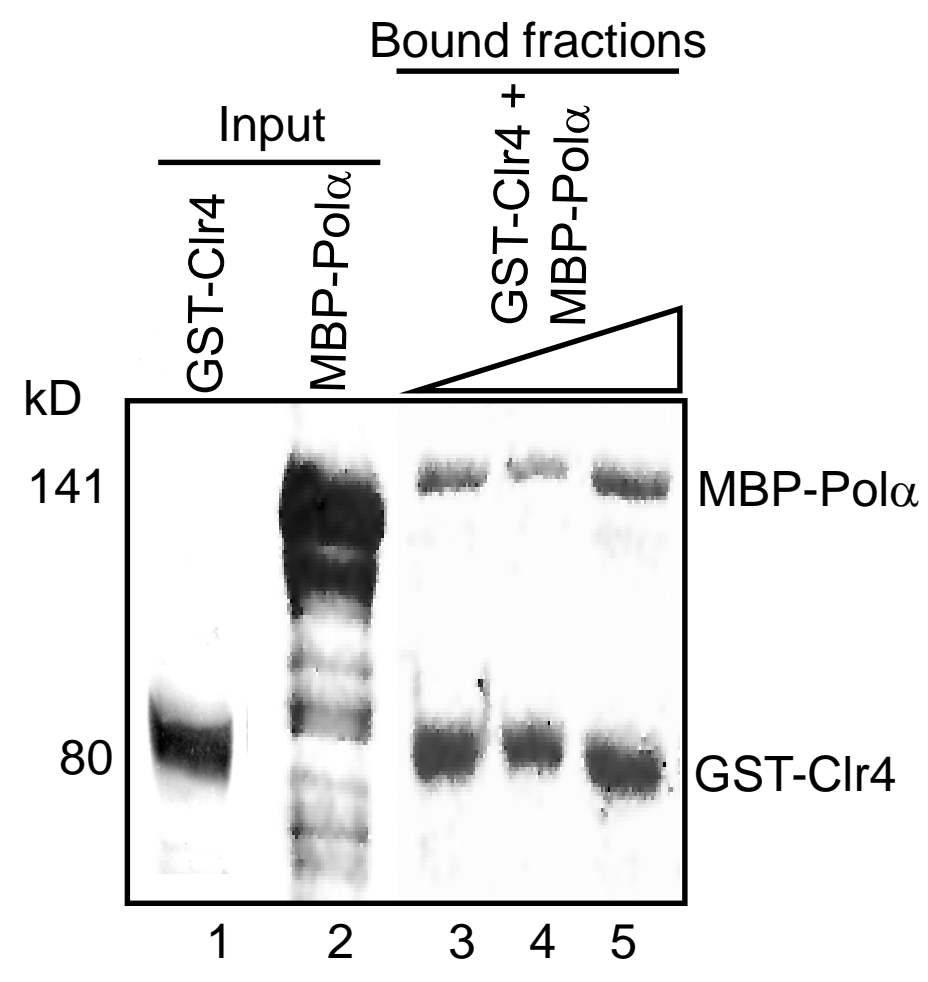

B

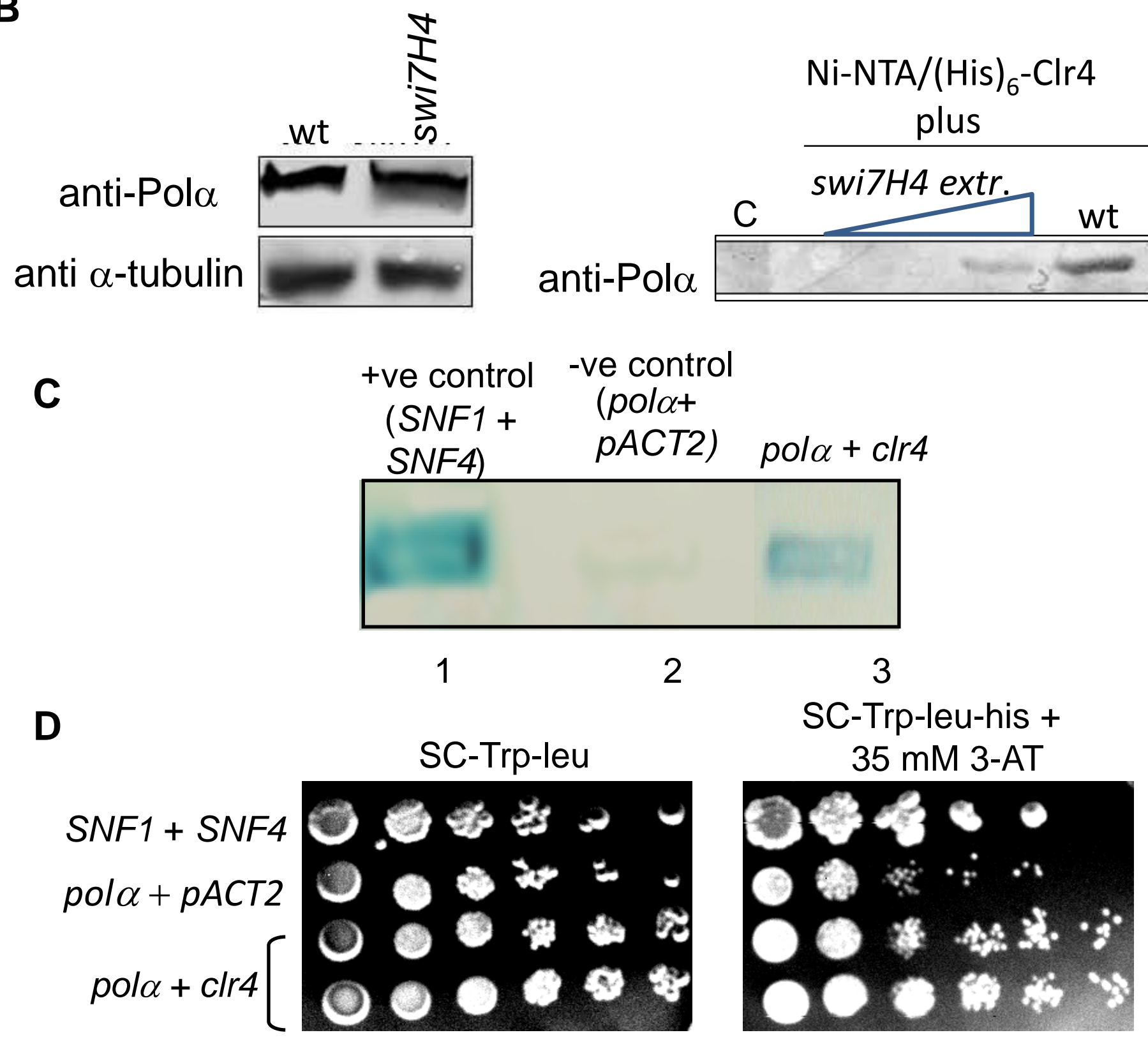


A

perpetuity. It is made available under aCC-BY-NC-ND 4.0 International license.

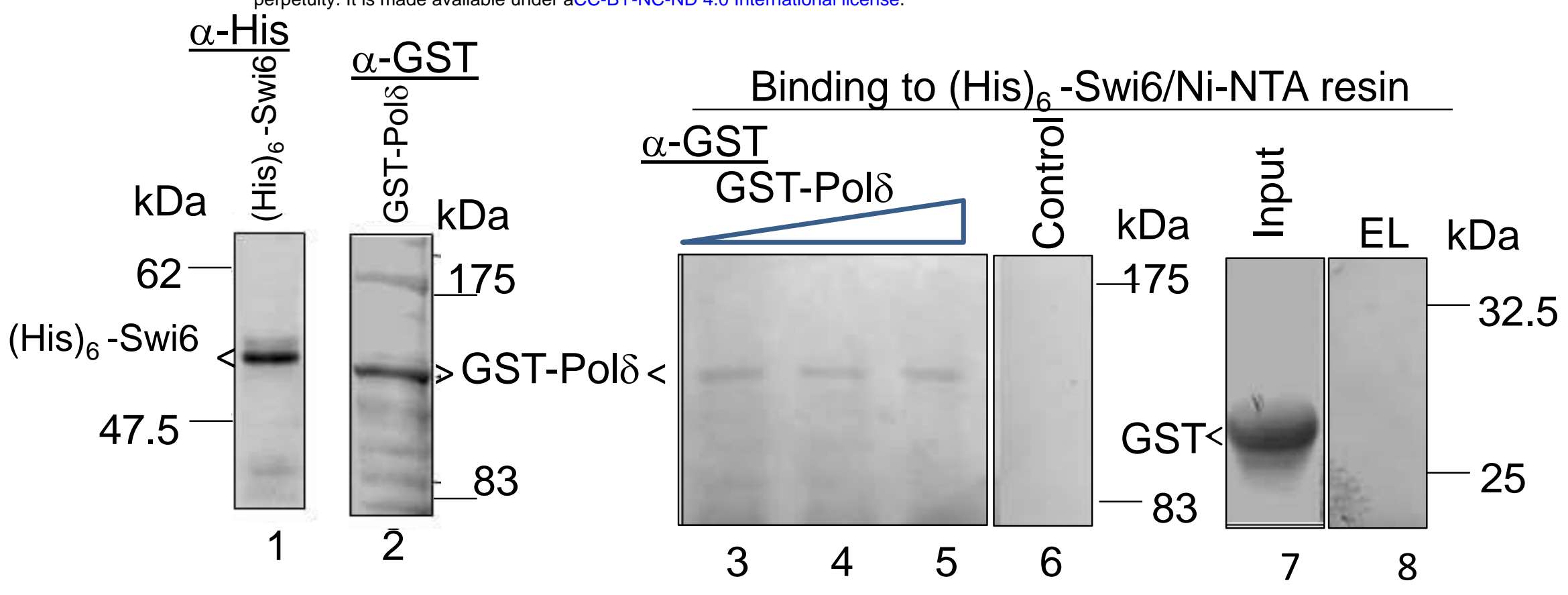

B

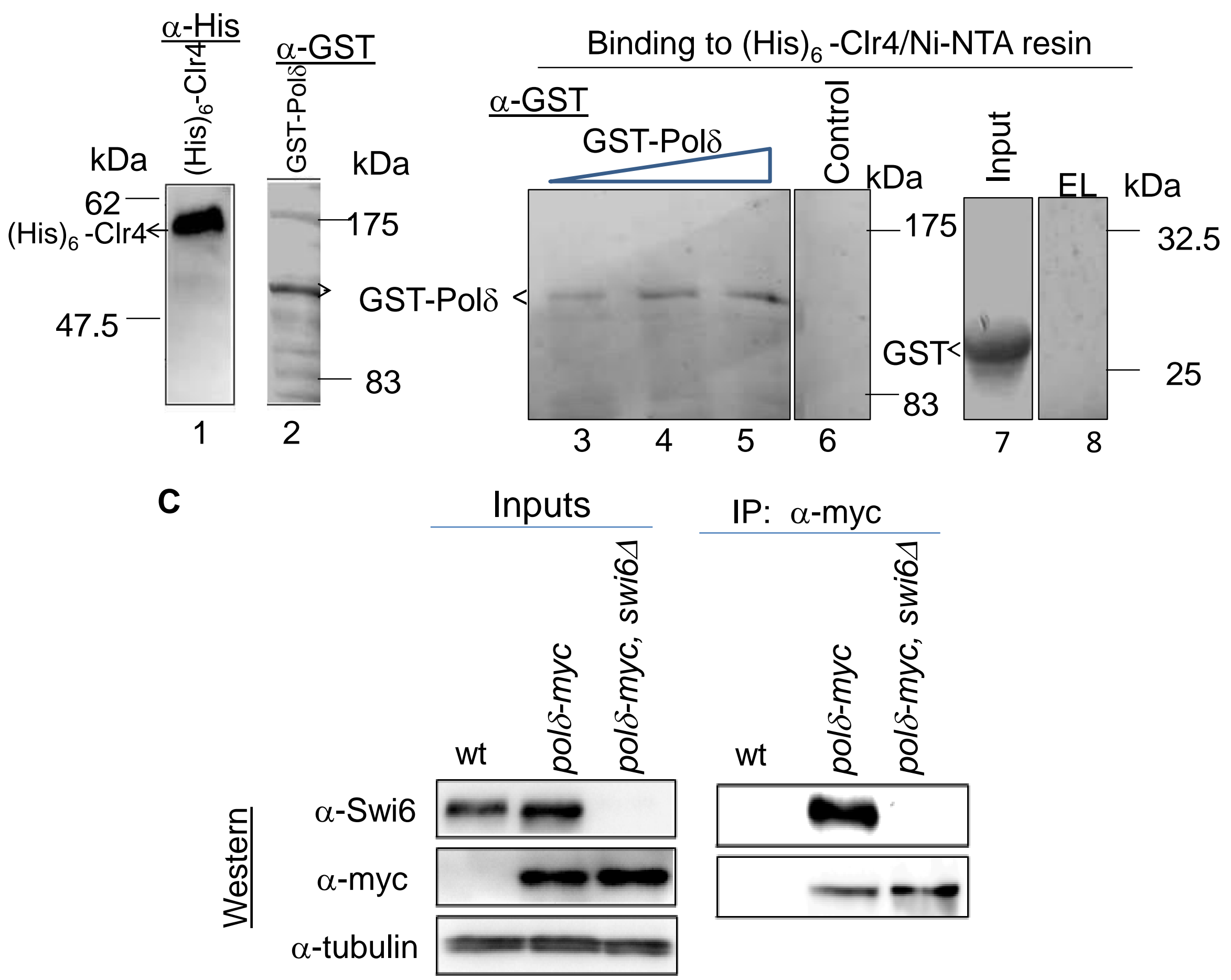


A

$\mathcal{C}$

$\frac{\sigma}{0}$

Phase tubulin DAPI merged

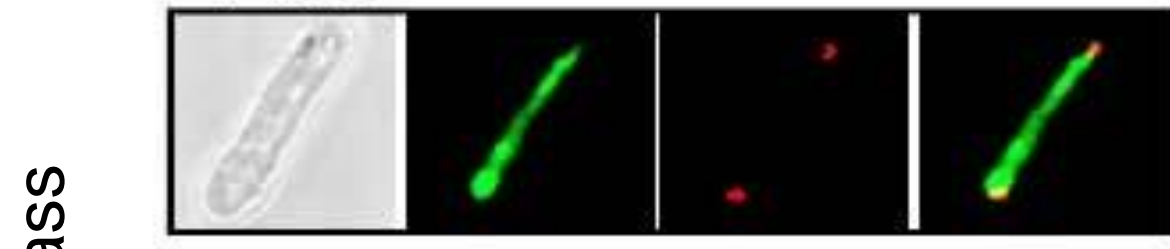

Sts 1

I

II

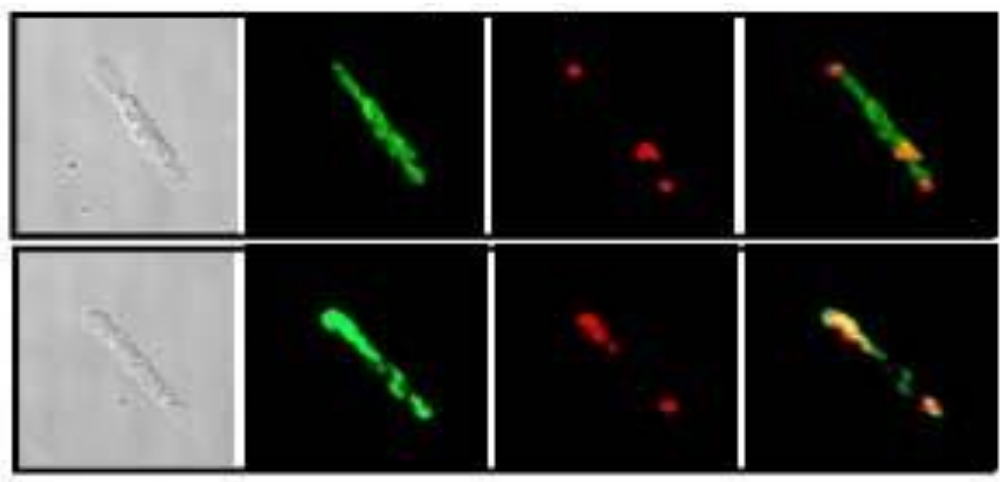

Sts2

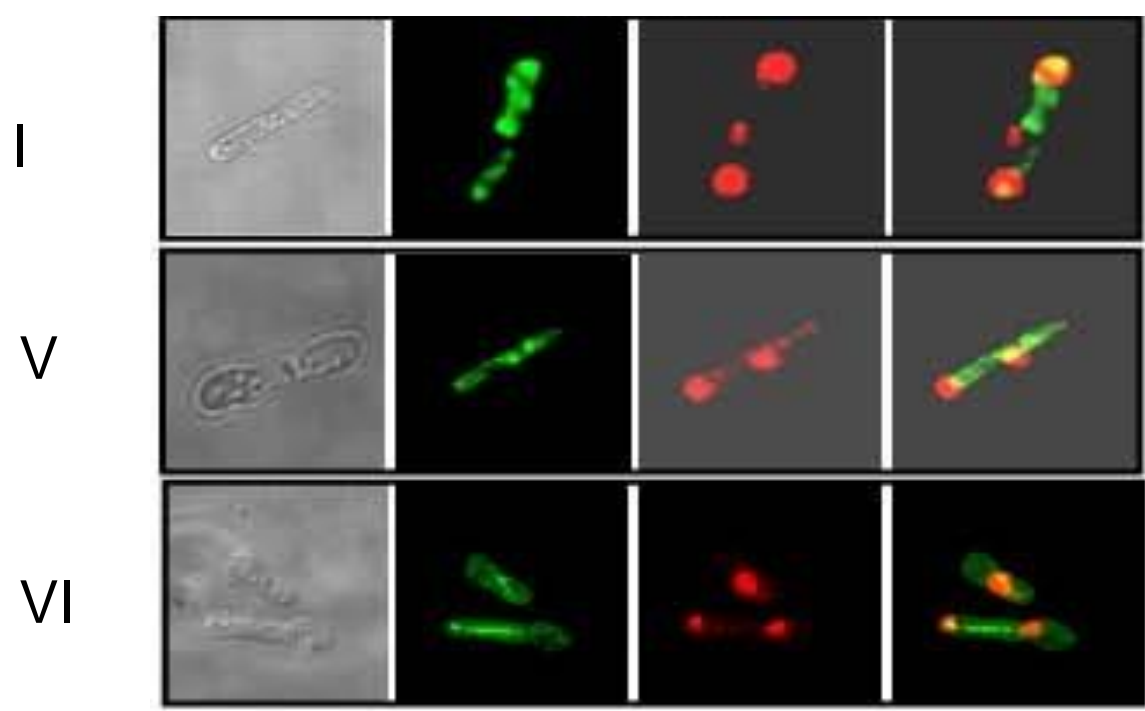

B

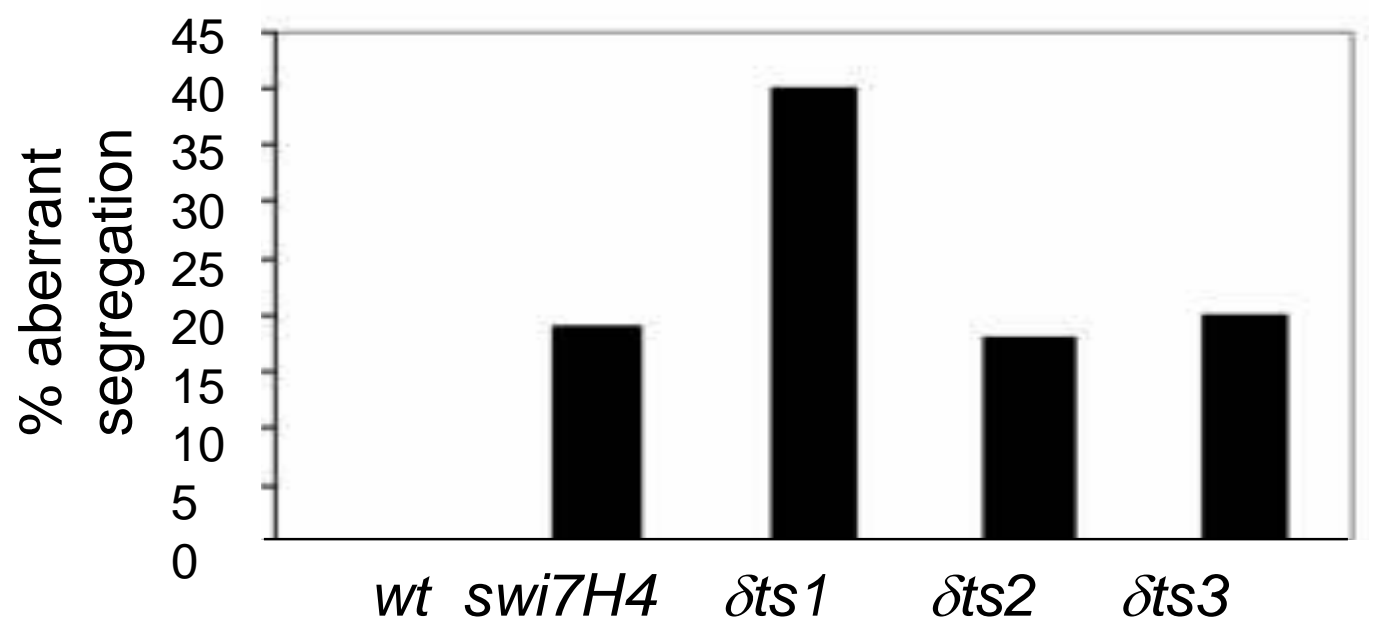

Sts3

$\frac{\widetilde{\sigma}}{0}$

$\circlearrowleft$ Phase tubulin DAPI merged

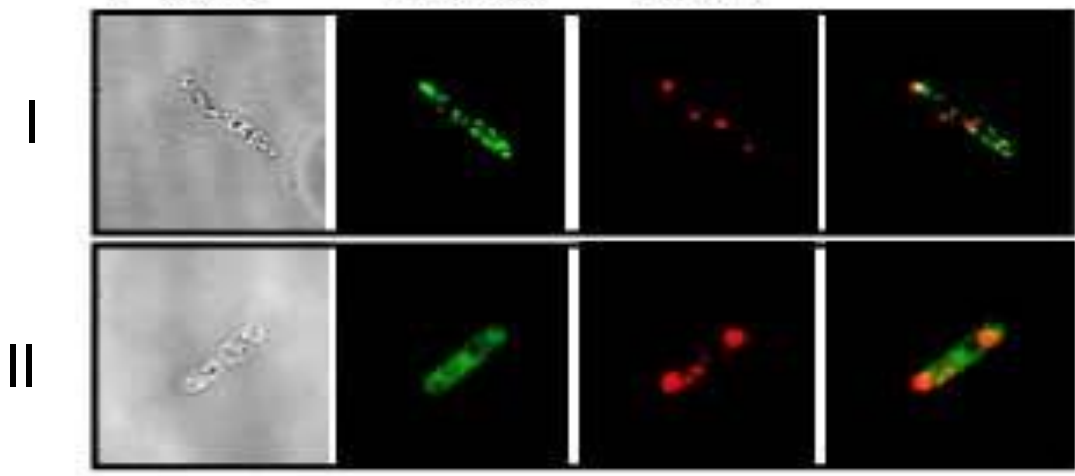

III

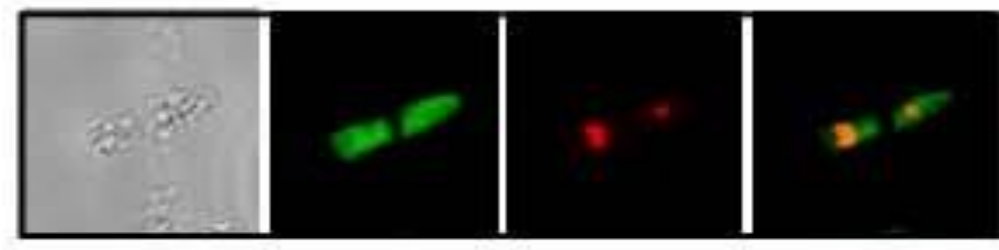

V

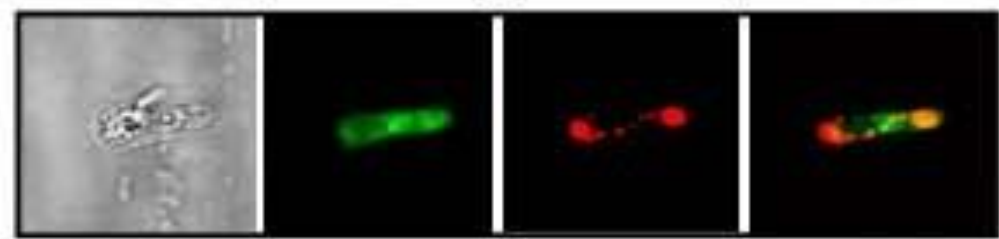

II

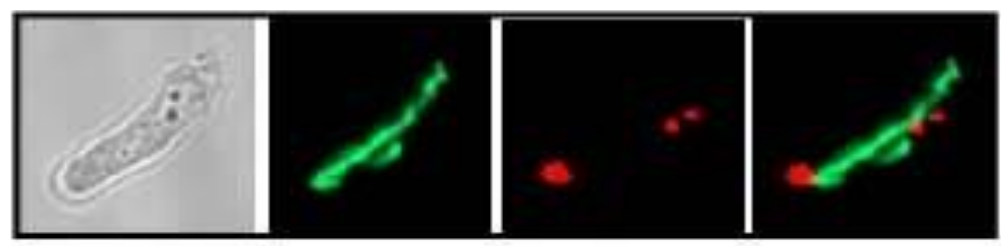

III
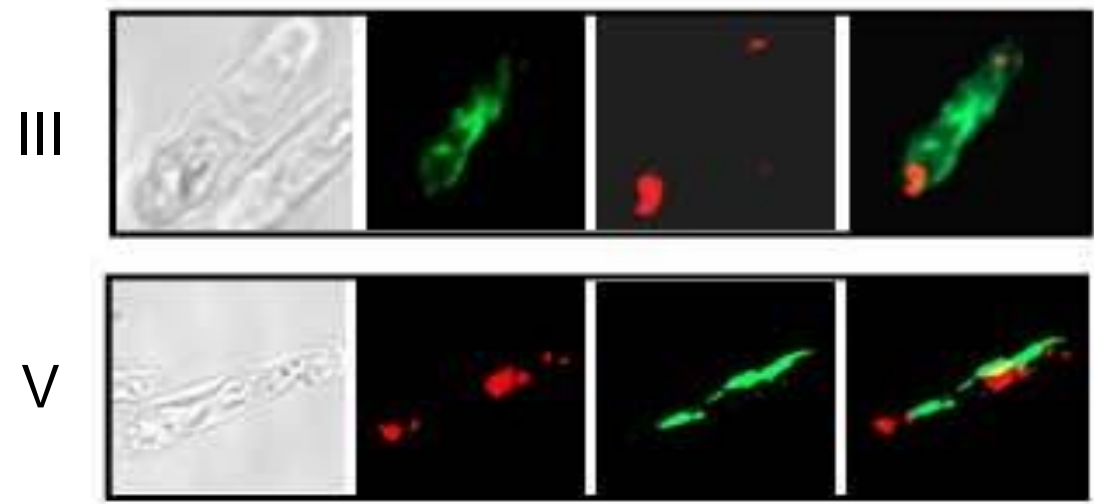


\begin{tabular}{|c|c|c|c|c|c|c|c|c|}
\hline \multirow[t]{2}{*}{ Class } & \multirow{2}{*}{\multicolumn{2}{|c|}{ Zygotic asci }} & & \multicolumn{5}{|c|}{$\%$ Total asci } \\
\hline & & & & $w t$ & switH4 & $\delta t s 1$ & $\delta t s 2$ & $\delta t s 3$ \\
\hline Normal & & & $0^{\circ} \cdot$ & 100 & 80.9 & 82.4 & 86.2 & 74 \\
\hline I & 080 & 4 & 60. & & 1.3 & 3.8 & 1.3 & 4 \\
\hline II & (3) & & 62 & & 12.7 & 10.8 & 9.2 & 7 \\
\hline III & & & 69. & & 5.1 & 1.5 & 3.3 & 11 \\
\hline DNA outside spores & $-\theta^{3}$ & $064^{4}$ & $\because \because$ & & 0.8 & & & 4 \\
\hline
\end{tabular}




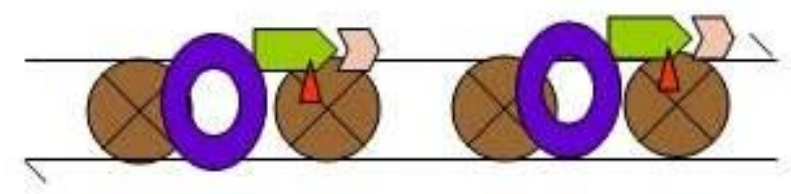

Pre-replicative heterochromatin

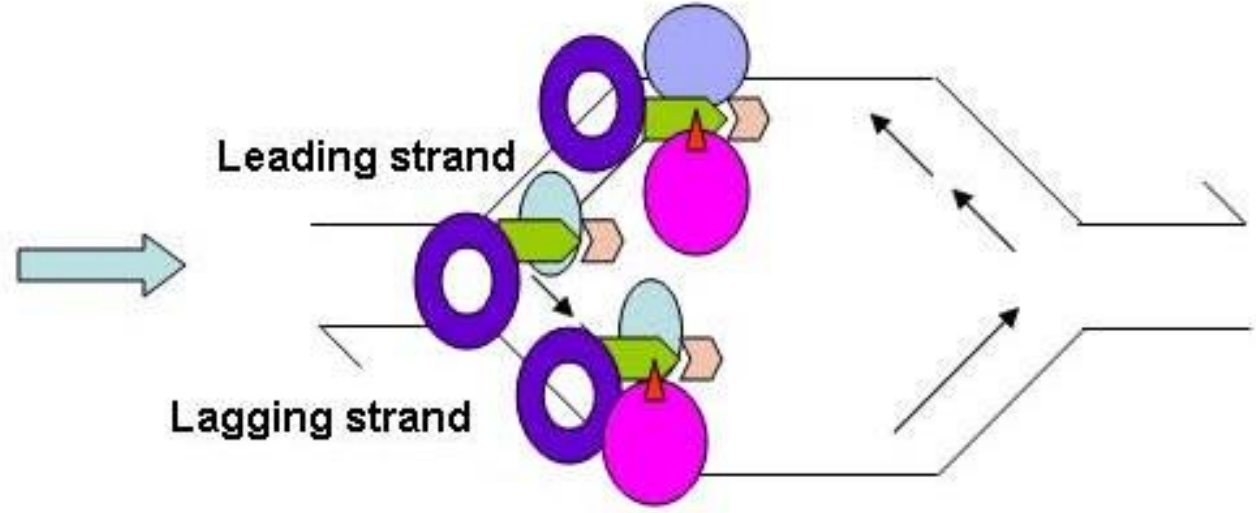

Replicative heterochromatin

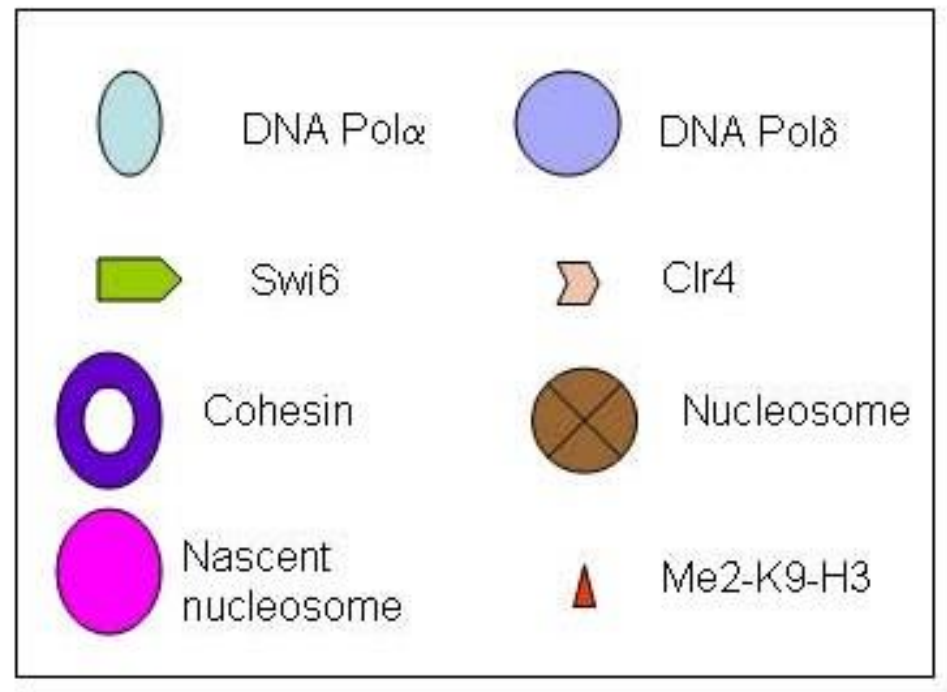

